Universidad de Lima

Facultad de Ingeniería y Arquitectura

Carrera de Ingeniería de Sistemas

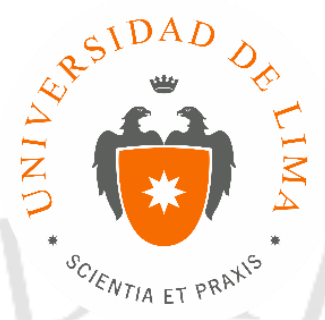

DESARROLLO DEL SISTEMA DE CONTROL SANCIONADOR DEL VICEMINISTERIO DE PESCA Y ACUICULTURA DEL MINISTERIO DE LA PRODUCCIÓN

Trabajo de suficiencia profesional para optar el Título Profesional de Ingeniero de Sistemas

Hugo Alberto Matsuura Garro Código 19912421

\title{
Asesor
}

Luis Armando Raygada Vargas

$$
\text { Lima - Perú }
$$

Noviembre de 2018 


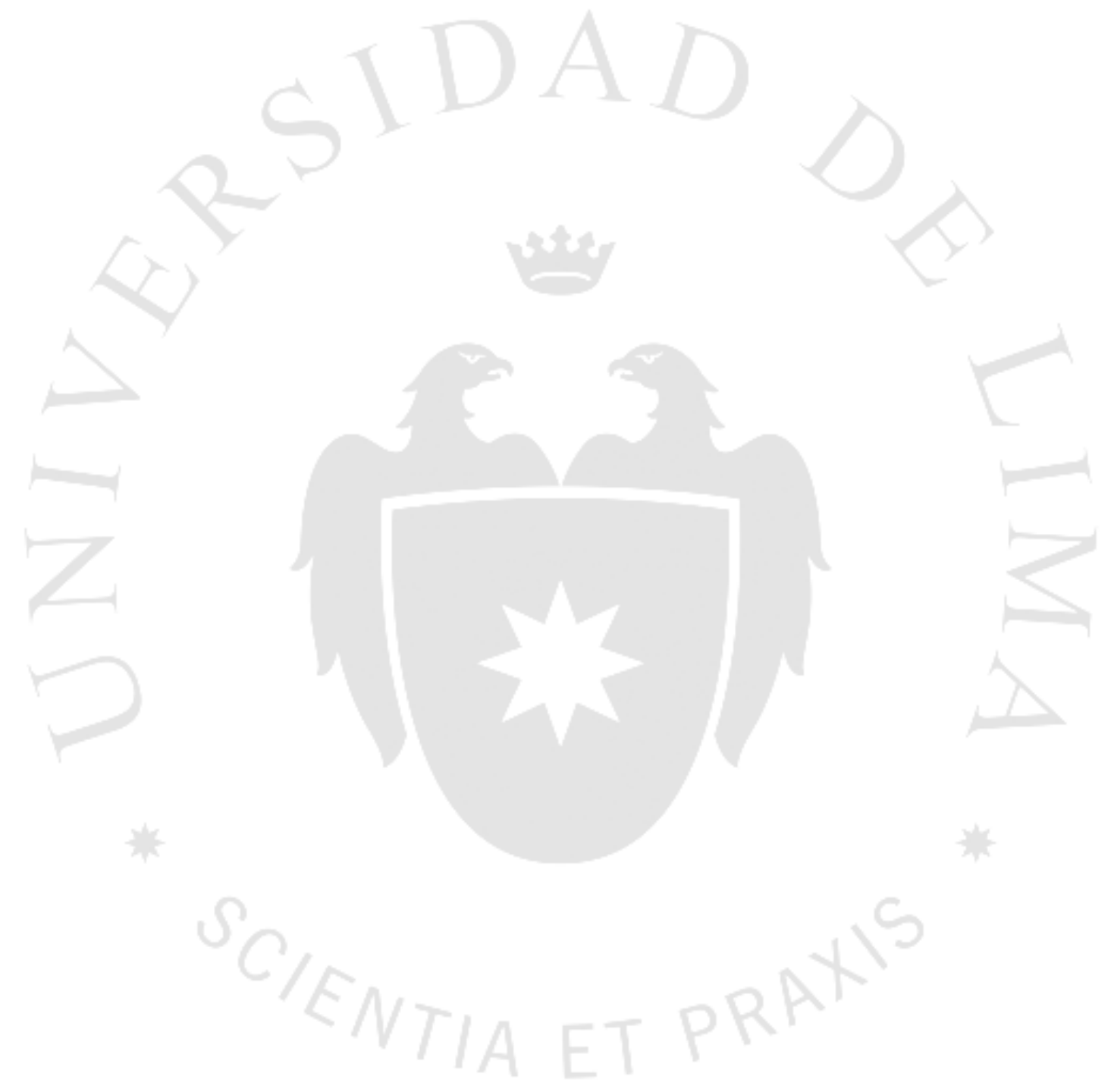




\section{DESARROLLO DEL SISTEMA DE CONTROL SANCIONADOR DEL VICEMINISTERIO DE PESCA Y ACUICULTURA DEL MINISTERIO DE LA PRODUCCIÓN}




\section{TABLA DE CONTENIDO}

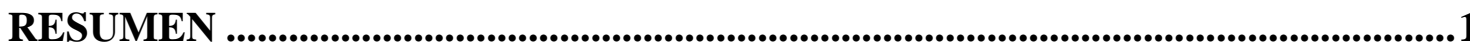

ABSTRACT

CAPÍTULO I: INTRODUCCIÓN .........................................................................3

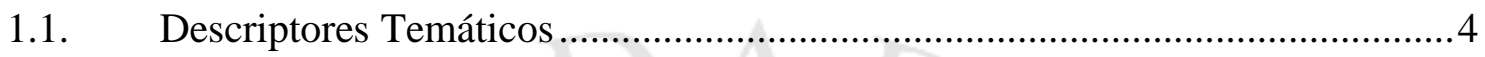

CAPÍTULO II: PROBLEMÁTICA .....................................................................5

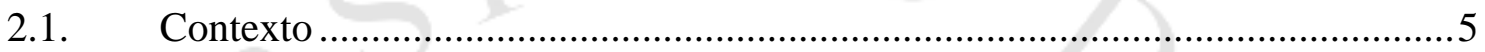

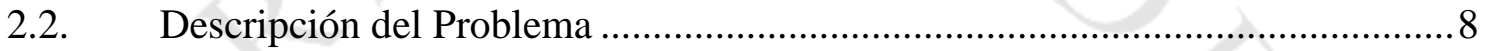

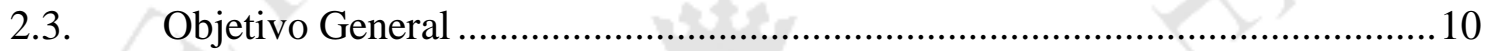

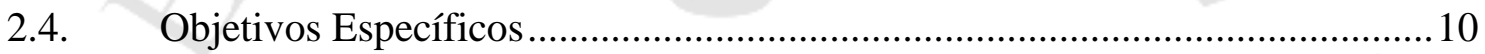

CAPÍTULO III: DEFINICIÓN DEL PROYECTO ................................................. 12

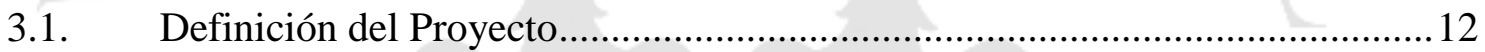

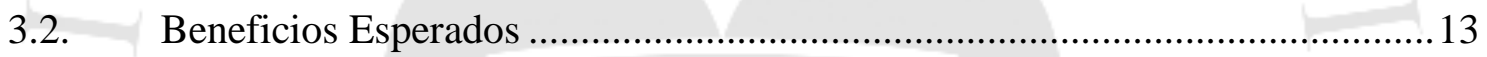

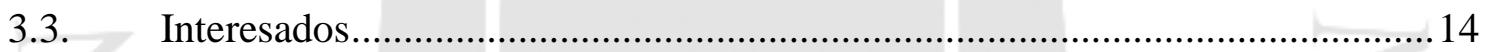

3.3.1. Áreas Impactadas y Principales Representantes ........................................... 14

3.3.2. Organigrama y Matriz RACI del Proyecto …................................................. 15

3.3.3. Descripciones de las funciones del Bachiller en el Proyecto Profesional........ 17

3.3.4. Aporte del Bachiller en el Proyecto Profesional ............................................. 17

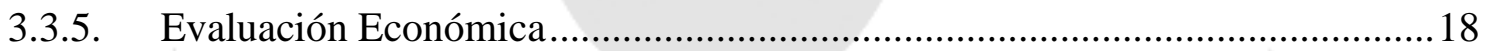

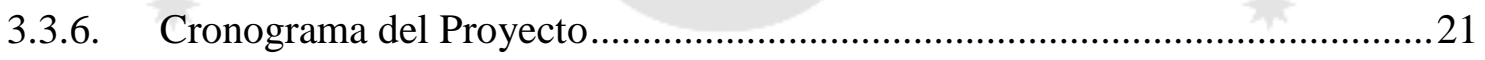

CAPÍTULO IV: DESARROLLO DEL PROYECTO............................................22

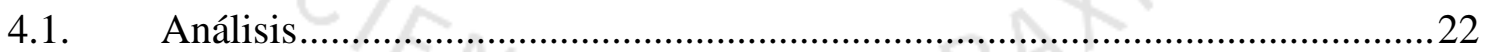

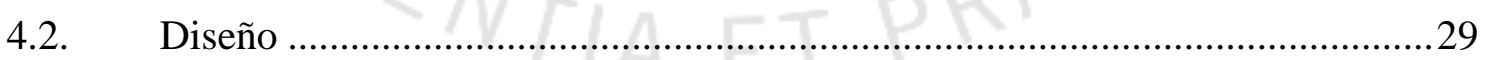

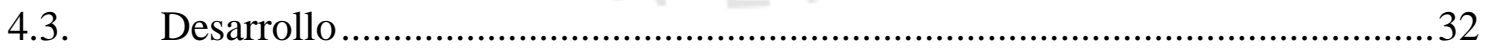

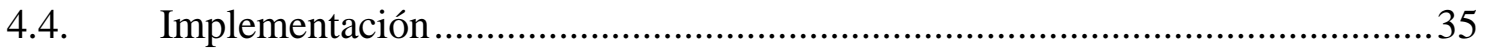

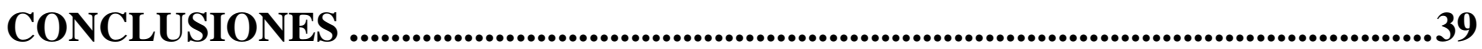

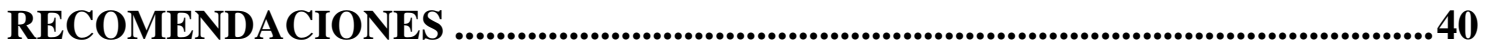

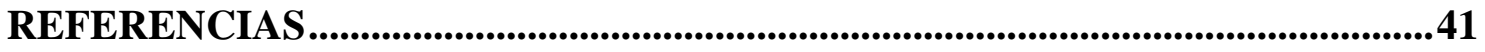




\section{INDICE DE TABLAS}

Tabla 3.1 Unidades Orgánicas del proceso administrativo sancionador .12

Tabla 3.2 Matriz RACI del proyecto 16

Tabla 3.3 Costos de recursos humanos del proyecto .18

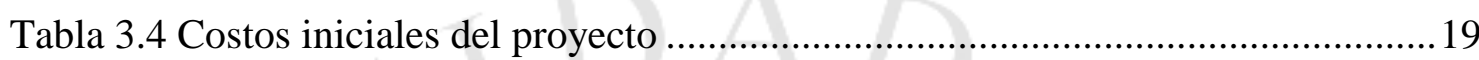

Tabla 3.5 Cálculo de sanciones impuestas y prescritas .................................................20

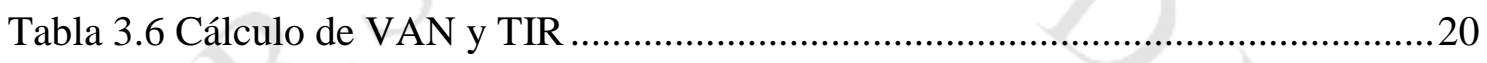




\section{INDICE DE FIGURAS}

Figura 3.1 Diagrama de intercambio de información con otros sistemas....................... 13

Figura 3.2 Organigrama del Ministerio de la Producción ............................................. 15

Figura 3.3 Organigrama del proyecto CONSAV ..................................................... 16

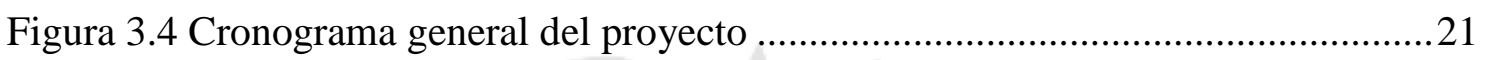

Figura 4.5 Flujo del proceso administrativo sancionador ..........................................22

Figura 4.6 Principales procesos de la Dirección de Sanciones.......................................23

Figura 4.7 Interface de la consulta general de información........................................... 30

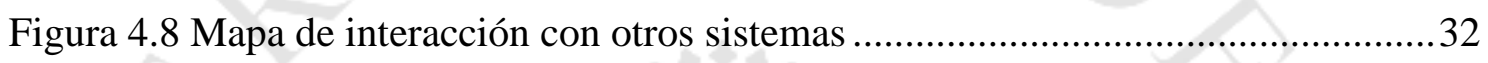

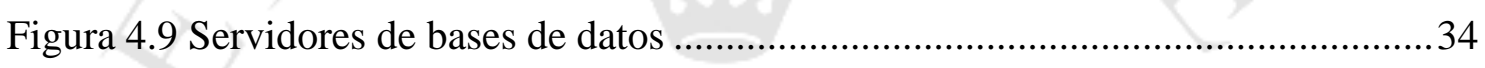

Figura 4.10 Cantidad de expedientes creados......................................................... 36

Figura 4.11 Consulta en el portal del Ministerio de la Producción .................................37

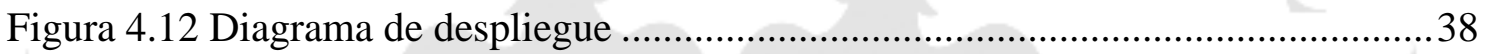




\section{INDICE DE ANEXOS}

Anexo 1: Diagrama General del Proceso Administrativo Sancionador Pesquero

Anexo 2: Cantidad de Procesos de Fiscalización y Multas .44

Anexo 3: Diagrama de Ishikawa .45

Anexo 4: Cronograma Detallado del Proyecto .46

Anexo 5: Flujo del Procedimiento Administrativo Sancionador.

Anexo 6: Diagramas de Casos de Uso

Anexo 7: Caso de Uso - Notificar un Expediente Sancionador. .54

Anexo 8: Caso de Uso - Crear Expediente Coactivo …...................................................56

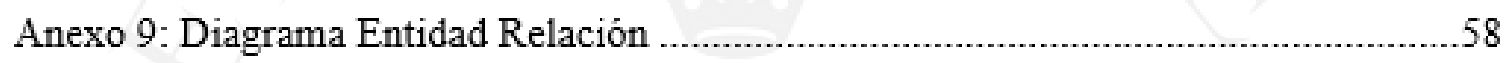

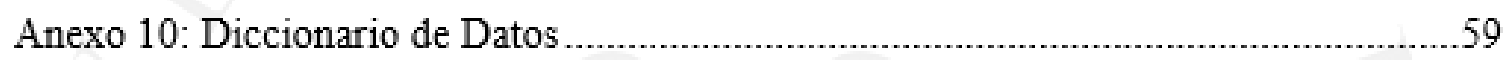

Anexo 11: Interface de la Intranet del Ministerio de la Producción ...............................64

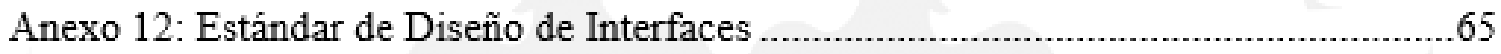

Anexo 13: Solicitud de Pase a Producción ...................................................................67

Anexo 14: Servidores y Diagrama de Red del Ministerio de la Producción ...................68

Anexo 15: Integridad de Información entre el sistema CONSAV y SITRADOC...........70

Anexo 16: Consulta de Información del Proceso Administrativo Sancionador en el portal del Ministerio de la Producción 71

Anexo 17: Formato de Memorando Generado por el sistema CONSAV ..........................72

Anexo 18: Consulta de Expedientes que tiene los abogados .........................................73 


\section{RESUMEN}

El presente trabajo fue desarrollado en el Ministerio de la Producción, por la Oficina General de Tecnologías de la Información, que de acuerdo a su Reglamento de Organización y Funciones es la responsable de implementar el gobierno electrónico en este Ministerio.

El objetivo principal de este presente proyecto fue la sistematización del proceso administrativo sancionador del ámbito pesquero y acuícola, a través del desarrollo e implementación de una herramienta informática que permita registrar toda la información del actual proceso e inclusive la histórica.

Este proyecto se desarrolló entre los años 2012 y 2013, en un periodo de 10 meses; contando para ello con un jefe de proyecto, un administrador de base de datos, un analista de sistemas, función que realizó mi persona, cuatro programadores, un encargado de infraestructura y un personal de calidad.

El proyecto se desarrolló a solicitud de urgencia del Viceministerio de Pesca y Acuicultura, donde los recursos utilizados fueron básicamente proporcionados por la Oficina General de Tecnologías de la Información, a excepción de dos programadores y sus correspondientes recursos, los cuales fueron necesarios de adquirir incurriendo en un costo de $\mathrm{S} / 25,000.00$ soles.

El proyecto contempla el desarrollo de los módulos para cada una de las unidades orgánicas que participan en este proceso, es así como se desarrollaron los módulos del proceso de fiscalización, de sanción, de apelación y de cobranza coactiva; pero además se desarrollaron las interfaces necesarias para intercambiar información con otros procesos ya establecidos.

Con este proyecto se logró poder registrar toda la información del proceso sancionador, además de agilizar la ejecución del proceso gracias a los formatos preestablecidos que se desarrollaron; esto también permitió bajar la cantidad de procesos de prescripción con lo cual se elevó la recaudación por concepto de multas. 


\begin{abstract}
The present work was developed in the Ministry of Production, by the General Office of Information Technologies, which according to its Regulation of Organization and Functions is responsible for implementing electronic government in this Ministry.

The main objective of this project was the systematization of the sanctioning administrative process of the fishing and aquaculture area, through the development and implementation of a computer tool that allows registering all the information of the current process and even the historical one.
\end{abstract}

This project was developed between 2012 and 2013, in a period of 10 months; counting with a project manager, a database administrator, a systems analyst, a function performed by myself, four programmers, an infrastructure manager and a quality staff.

The project was developed at the urgency request of the Vice Ministry of Fisheries and Aquaculture, where the resources used were basically provided by the General Office of Information Technologies, except for two programmers and their corresponding resources, which were necessary to acquire incurring in a cost of $\mathrm{S} /$ $25,000.00$ soles.

The project contemplates the development of the modules for each of the organic units that participate in this process, this is how the modules of the inspection, sanction, appeal and coercive collection processes were developed; but also the necessary interfaces were developed to exchange information with other processes already established.

With this project it was possible to register all the information of the sanctioning process, in addition to streamlining the execution of the process thanks to the preestablished formats that were developed; This also allowed to lower the amount of prescription processes which raised the collection of fines. 


\section{CAPÍTULO I: INTRODUCCIÓN}

En diciembre del año 1992 se emitió el Decreto Ley No 25977 - Ley General de Pesca, teniendo como objeto normar la actividad pesquera con el fin de promover su desarrollo sostenido como fuente de alimentación, empleo e ingresos y de asegurar un aprovechamiento responsable de los recursos hidrobiológicos. Sin embargo recién en el año 2001, se aprobó su Reglamento a través del Decreto Supremo No 012-2001-PE, la cual estableció las infracciones y sanciones administrativas de la actividad pesquera.

Como en muchos de los procedimientos del Estado, el proceso sancionador del ámbito pesquero y acuícola se inició de manera manual, pero dado el incremento de las sanciones impuestas se volvió muy tedioso de poderlos administrar en forma adecuada, por lo que se tuvo que pensar en desarrollar un aplicativo informático.

Luego de varios intentos por desarrollar una aplicación para que se sistematice el proceso sancionador, especialmente a través de servicio de terceros, en el año 2012 se encarga a la Oficina General de Tecnologías de Información el desarrollo de un aplicativo informático para sistematizar los principales procedimientos que la norma establecía. Es así como se inicia el proyecto informático para sistematizar la información del proceso sancionador llevado a cabo por las Unidades Orgánicas del Despacho Viceministerial de Pesca y Acuicultura del Ministerio de la Producción.

El objetivo es sistematizar el proceso sancionador, permitiendo registrar la información actual e histórica de los procesos sancionadores del ámbito pesquero y acuícola. Mostrando que el proceso sancionador es un macro proceso, y que a través de un aplicativo informático se brinde una mayor interacción entre las Unidades Orgánicas, ya sea que éstas participen directamente o indirectamente en este proceso, dado que la información de una depende o está relacionada a otra Unidad Orgánica.

En el Capítulo II se describe la problemática del Viceministerio de Pesca y Acuicultura y de sus Unidades Orgánicas que motivó la realización del proyecto y los objetivos asociados. 
En el Capítulo III se define el proyecto, mencionando las Unidades Orgánicas del Ministerio de la Producción que se beneficiaron con la implementación del proyecto, asimismo se describe el organigrama y la participación del bachiller en desarrollo del proyecto. También se detallan la evaluación económica y el cronograma del proyecto.

El Capítulo IV contiene el detalle de lo realizado en cada fase del proyecto de implementación haciendo hincapié en los riesgos y retos enfrentados en cada uno de estas fases.

Finalmente, se incluyen las conclusiones del proyecto una vez finalizada la participación del bachiller y las recomendaciones deducidas a partir de las lecciones aprendidas y que puedan aplicar a proyectos de características similares.

\subsection{Descriptores Temáticos}

- Administrado

- Casos Uso

- Diccionario de Datos

- Infracción

- Multas

- Proceso Administrativo

- Proceso de Apelación

- Proceso de Ejecución Coactivo

- Sanción

- Sistemas de Información

- Unidades Orgánicas 


\section{CAPÍTULO II: PROBLEMÁTICA}

\subsection{Contexto}

En el año 1997 se emitió el Decreto Ley Nº 25977 - Ley General de Pesca, la cual tiene por objeto normar las actividades pesqueras con el fin de promover su desarrollo sostenido como fuente de alimentación, empleo e ingresos, asegurando un aprovechamiento responsable de los recursos hidrobiológicos que tiene el Perú, optimizando los beneficios económicos, en armonía con la preservación del medio ambiente y la conservación de la biodiversidad.

Es así como a través de este Decreto Ley, de su Reglamento (inicialmente aprobado mediante Decreto Supremo No 021-2001-PE) y sus modificatorias dadas en adelante, es que se define el proceso sancionador del ámbito pesquero.

El Ministerio de la Producción fue creado el 10 de julio de 2002 mediante Ley No 27779. Tiene como finalidad diseñar, establecer, ejecutar y supervisar, en armonía con la política general y los planes de gobierno, política nacionales y sectoriales aplicables a los sectores de pesquería y de MYPE e industria, asumiendo rectoría respecto de ellas. Dicta normas y lineamientos técnicos para la adecuada ejecución y supervisión de las políticas, la gestión de los recursos del Sector, así como para el otorgamiento, reconocimiento de derechos, la sanción, fiscalización y ejecución coactiva.

El ámbito del Ministerio de la Producción es el siguiente:

- Subsector MYPE e Industria: comprende el fomento de la iniciativa empresarial, la competitividad de la micro y pequeña empresa, la asociatividad y el cooperativismo, así como las actividades de industrialización, procesamiento y manufactura, velando por el aprovechamiento sostenible de los recursos naturales y la protección del ambiente.

- Subsector Pesquería: todos los recursos de origen hidrobiológico contenidos en las aguas marinas jurisdiccionales, ríos, lagos y otras fuentes hídricas del territorio nacional. Comprende la investigación científica y tecnológica del 
sector pesquería; así como las condiciones ecológicas de su hábitat; los medios para su conservación y explotación, la calidad, higiene y sanidad de los productos de procedencia acuática; la infraestructura pesquera, así como los servicios adicionales y complementarios para la realización de las actividades extractivas, acuícolas y del proceso pesquero en general. Postula las políticas para la promoción del Perú como país oceánico y el uso de recursos hidrobiológicos para el consumo humano.

El Ministerio de la Producción tiene entre sus principales funciones la de establecer el marco normativo para el desarrollo de las actividades extractivas, productivas y de transformación de los subsectores pesquería e industria, así como fiscalizar y supervisar el cumplimiento de las mismas, incluyendo las actividades productivas que se desarrollen en las Zonas Francas, Zonas de Tratamiento Especial Comercial y Zonas Especiales de Desarrollo, en coordinación con los organismos competentes en esta materia.

El procedimiento sancionador se inicia con el procedimiento de fiscalización, función que realiza en la actualidad la Dirección de Supervisión y Fiscalización (DSFPA), y en el cual se establece si una embarcación, o establecimiento pesquero, o persona natural o jurídica en general ha cometido una falta o infracción de acuerdo a lo establecido en esta normatividad. Con esta información se crea un expediente sancionador que luego de ser evaluado por un área legal se emite la Resolución Directoral correspondiente; función que en la actualidad realiza la Dirección de Sanciones (DS-PA); una vez emitida la sanción ésta es comunicada al administrado (persona natural o jurídica) a través de una cédulas de notificación. Por su parte el administrado tiene el derecho de apelar la sanción impuesta, la cual es tramitada por una segunda instancia administrativa, función que en la actualidad la realiza el Consejo de Apelación de Sanciones (CONAS), la cual determina si es fundado o infundada la apelación presentada por el administrado. En el caso que sea infundada la apelación, ésta continúa con el proceso sancionador remitiéndose la información al proceso de cobro de la multa impuesta, función que realiza la Oficina de Ejecución Coactiva (OEC) en la actualidad.

Adicionalmente, durante la ejecución del proceso sancionador se interactúa con otros procesos administrativos del Ministerio de la Producción, tal es el caso del procedimiento de emisión de documentos el cual es realizado por el Sistema de Trámite 
Documentario (SITRADOC) a cargo de la Oficina General de Atención al Ciudadano (OGACI), teniendo como principal función de numerar y relacionar toda la documentación que se genera o se recibe en el Ministerio de la Producción. También se interactúa con el procedimiento de recaudación a cargo de la Oficina de Tesorería (OT) para efectos de identificar los depósitos realizados en las cuentas que tiene el Ministerio en los bancos a nivel nacional, o lo recibido a través de caja del propio Ministerio. Finalmente la información registrada en el proceso sancionador sirve para otorgar el derecho de autorización de una embarcación pesquera para a realizar faenas de pesca o no, como también si una planta pesquera puede continuar con el procesamiento de productos hidrobiológicos marítimos o continentales, para lo cual se verificará si tiene o no alguna multa pendiente por pagar.

Durante la ejecución del proceso sancionador es necesario comunicar a otras entidades externas del Ministerio de la Producción la emisión de una sanción impuesta, tal es el caso de la suspensión de actividades a embarcaciones pesqueras, las cuales se comunica mediante Oficio a la Dirección General de Capitanía de Puertos y Guardacostas del Perú (DICAPI), función que en la actualidad la realiza la Dirección General de Pescar para Consumo Humano Directo e Indirecto (DGPCHDI).

Se adjunta en el Anexo $\mathrm{N}^{\circ}$ 1, un diagrama que grafica el flujo del proceso administrativo sancionador pesquero a nivel general, en el cual se muestra las Unidades Orgánicas que en la actualidad tienen a cargo la ejecución de este proceso en el Ministerio de la Producción.

Para comprender la magnitud del proceso sancionador, es preciso señalar que un 90\% de actividades de fiscalización realizadas a nivel nacional, se convierten en un proceso sancionador, lo cual involucra un promedio de 8,000 UIT de sanciones impuestas al año, generando una cuantiosa cartera por cobrar; ver en el Anexo $N^{\circ} 2$ la cantidad de procesos sancionadores del periodo 2008 al 2012.

Como antecedentes previos a la implementación de este sistema, se tiene que en el año 2008 se implementó el Sistema del Proceso Sancionador (SIPROSAC), el cual tenía por objetivo registrar la información del proceso sancionador pesquero; debiendo ser implementado para ser utilizado por la ex Dirección General de Seguimiento de Control, Supervisión y Vigilancia (DIGSECOVI), la cual tenía como unidades de línea a la Dirección de Supervisión y Fiscalización (DSF), y a la Dirección de Sanciones (DS); 
sin embargo no pudo ser implementado en el ex Consejo de Apelación de Sanciones (CAS), y tampoco en la Oficina de Ejecución Coactiva (OEC); por lo que en éstas últimas Unidades Orgánicas se registraba la información del proceso sancionador en sus propios formatos, archivos en Excel, en texto, en Word y hasta en base de datos Access, en algunos casos.

La información que se tenía de los procesos sancionadores pesqueros estaba en forma dispersa, no relacionada, donde muchos de sus colaboradores (trabajadores) de la Unidades Orgánicas involucradas en el proceso, tenían su propia información, con sus propios estilos y formatos, y que en la mayoría de veces ésta no correspondían con la que tenía otro trabajador; encontrándose en muchos casos que los colaboradores eran recelosos de mostrar o compartir su información. No se conceptualizaba el proceso sancionador como un solo macro proceso.

Es bajo este contexto que en el año 2012 el Viceministerio de Pesquería, de ese entonces, contrata el servicio para crear un nuevo sistema con la finalidad de ampliar el alcance del sistema SIPROSAC, sin embargo a los 6 meses de iniciado dicho proyecto, éste no mostraba avance en su desarrollo, por lo que las autoridades de dicho Viceministerio, de ese momento, solicitaron a la Oficina de Informática iniciar el desarrollo de un nuevo sistema informático con sus propios recursos.

Es así que en el mes de agosto del año 2012 se inicia el proyecto del Sistema de Control Sancionador Virtual (CONSAV) el cual implementó sus dos primeros módulos, el de fiscalización y el sanción a inicios del año 2013, para uso de la actual Dirección de Sanciones (DS-PA), y que luego continuó con el desarrollo del Módulo de Apelaciones y finalmente con el Módulo de Ejecución Coactiva.

\subsection{Descripción del Problema}

El problema principal es la deficiente gestión administrativa que realizan las Unidades Orgánicas del Ministerio de la Producción sobre el proceso sancionador pesquero, de acuerdo a lo establecido en el Decreto Ley No 25977 - Ley General de Pesca, en su Reglamento y sus modificatorias. 
Los procedimientos de fiscalización que se realizan en el ámbito pesquero, son el insumo para iniciar el procedimiento sancionador, estos son diferentes y constantemente varían en la forma de procesar la información. Estos procedimientos no están documentados, las Unidades Orgánicas involucradas no se han preocupado por hacer un relevamiento del flujo de información de su jurisdicción, y mucho menos se tiene un flujo global del proceso sancionador.

Por otro lado, como es conocido en el Estado, existe una constante rotación de colaboradores, especialmente de aquellos que tienen cargos de confianza, vale decir Viceministros, Directores Generales y Directores de Línea; estos cambios a su vez originaba que en muchos de los casos los colaboradores tampoco tengan una estabilidad laboral, vale decir aquellos que prestaban servicios al Estado en modalidad de terceros, eran cambiados por otros nuevos; todos estos cambios hacían variar la interpretación de la aplicación de las normas y en consecuencia el flujo de información que se debía desarrollar a través de un aplicativo informático.

Adicionalmente existe una problemática con la información del proceso sancionador, pues ésta se encuentra dispersa; una parte contenida en sistemas de información, vale decir en los sistemas de fiscalización, o por ejemplo en el Sistema de Trámite Documentario; pero además los mismos colaboradores que trabajaban en las diferentes etapas del procedimiento sancionador tenían su propia información, de acuerdo al trabajo que realizaban; esta información se encontraba en diferentes formatos, especialmente en formato Excel.

Además la información del proceso sancionador requiere de la interacción con otros procesos administrativos del Ministerio de la Producción; de manera que en unas veces el proceso sancionador requiere de información de un proceso, como por ejemplo de los reportes de ocurrencia contenidos en los sistema de fiscalización, como en otras el proceso sancionador brindaba de información para que otros procesos realicen un eficiente control, como por ejemplo el proceso de suspensión de embarcaciones.

La forma manual que se gestionaba la información de los procesos sancionadores hace que se almacenen físicamente en las Unidades Orgánicas responsables a cargo de llevar este proceso, información voluminosa la cual no se podía saber si estaba por prescribir o no. 
Finalmente, como toda normatividad que se emite en el Estado, ésta necesita de recursos para su implementación, sin embargo para el proceso sancionador no se tenía previsto un presupuesto para su implementación y mucho menos para un mantenimiento a largo plazo.

En el Anexo $N^{o} 3$ se muestra a través de un diagrama de Ishikawa el problema con sus principales causas que originan el problema del proceso administrativo sancionador del Ministerio de la Producción, en sus diferentes contextos: ambiente, procedimiento, personal, medida, información y recurso.

\subsection{Objetivo General}

El presente proyecto tiene como objetivo general la sistematización de proceso administrativo sancionador pesquero a través de una herramienta informática que permita registrar toda la información, inclusive la histórica.

\subsection{Objetivos Específicos}

- Permitir el registro de la información actual e histórica de los procesos sancionadores, registrando información en forma ordenada, coherente, relacionada y validada por las Unidades Orgánicas que participan en este proceso.

- Brindar información oportuna y confiable del proceso administrativo sancionador, pudiendo consultar la información de un proceso, independientemente de la etapa en la que éste se encuentre, haciendo pública y transparente su información. Ofreciendo información a otras Unidades Orgánicas que indirectamente participan del proceso sancionador, en la cual la información de éste proceso le es útil para sus propósitos; tal es el caso de la identificación de los pagos realizados en las cuentas que tiene el Ministerio en la banca nacional, la cual es identificada por la Oficina de Tesorería.

- Interactuar con otros sistemas implementados en el Ministerio de la Producción, evitando que el usuario registre la misma información en diferentes sistemas (evitar el doble registro), y respetando el procedimiento establecido en los otros procesos con los que se interactúa. 
- Agilizar el proceso sancionador, estandarizando formatos utilizados por las Unidades Orgánicas durante el proceso administrativo, pudiendo generar dichos formatos de manera electrónica.

- Otorgar seguridad tanto a la información del proceso sancionador permitiendo realizar trazabilidad de cada registro ingresado; así como también a la accesibilidad al sistema a través de su implementación en la intranet de Ministerio de la Producción, la cual solicita un usuario y contraseña para su uso. 


\section{CAPÍTULO III: DEFINICIÓN DEL PROYECTO}

\subsection{Definición del Proyecto}

El alcance del sistema CONSAV es permitirles a las Unidades Orgánicas que participan en el proceso sancionador del ámbito pesquero, registrar la información de dicho proceso.

Tabla 3.1

Unidades Orgánicas del proceso administrativo sancionador

\begin{tabular}{|l|l|}
\hline \multicolumn{1}{|c|}{ Unidad Orgánica } & \multicolumn{1}{c|}{$\begin{array}{c}\text { Descripción de la función que realiza en el proceso } \\
\text { sancionador }\end{array}$} \\
\hline $\begin{array}{l}\text { Dirección de Supervisión y } \\
\text { Fiscalización }\end{array}$ & $\begin{array}{l}\text { Determina el proceso de fiscalización y presenta los hechos } \\
\text { de la posible actividad ilícita realizada por el administrado. }\end{array}$ \\
\hline Dirección de Sanciones & $\begin{array}{l}\text { Es la primera instancia administrativa que determina si } \\
\text { amerita iniciar un proceso de sanción o no, en base a la } \\
\text { normatividad establecida, determinando la sanción a } \\
\text { imponer en el caso que si lo amerite. }\end{array}$ \\
\hline $\begin{array}{l}\text { Consejo de Apelación de } \\
\text { Sanciones }\end{array}$ & $\begin{array}{l}\text { Es una segunda instancia administrativa que evalúa la } \\
\text { sanción impuesta en base a la apelación presentada por el } \\
\text { administrado sancionado; emitiendo la ratificación } \\
\text { impuesta o solicitando la rectificación de la misma. }\end{array}$ \\
\hline Oficina de Ejecución Coactiva & \begin{tabular}{l} 
Realiza el proceso de cobranza de la multa impuesta \\
\hline
\end{tabular} \\
\hline
\end{tabular}

Fuente: Análisis del sistema CONSAV

Adicionalmente, el proceso sancionador interactúa con otros procedimientos de Ministerio de la Producción; como por ejemplo con el de Trámite Documentario, el cual se encarga de numerar toda la documentación que genera el proceso sancionador (informes, resoluciones, cédulas de notificación, memorando y oficios). También es necesario interactuar con el procedimiento de control pesquero, el cual brinda la información de la fiscalización realizada y a su vez el proceso sancionador le informa de aquellas embarcaciones, plantas pesqueras o administrados que están involucrados en un proceso administrativo de sanción. Asimismo debe interactuar con el proceso de contabilidad, a través del cual se realiza el control de pagos y deudas que tienen los administrados con el Ministerio. Finalmente el proceso sancionador interactúa con el 
proceso judicial el cual le informa de aquellos administrados que han iniciado una demanda en el Ministerio Público.

Figura 3.1

Diagrama de intercambio de información con otros sistemas

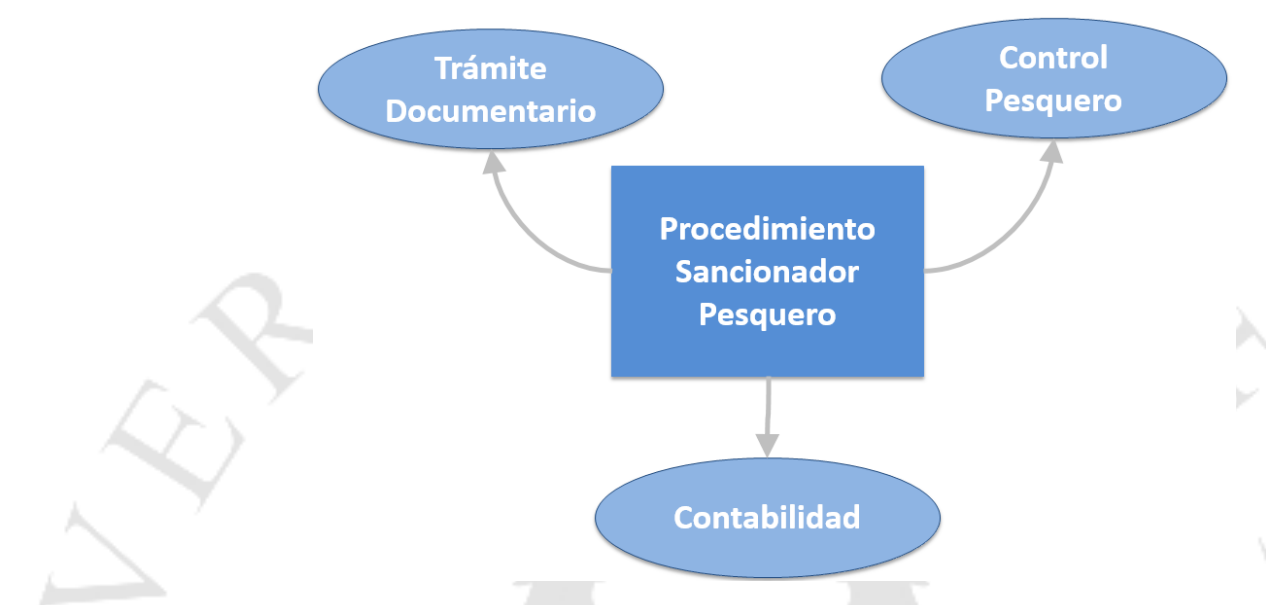

Fuente: Análisis del sistema CONSAV

\subsection{Beneficios Esperados}

De la sistematización del proceso sancionador, a través de la implementación del sistema CONSAV se espera:

- Permitir un mayor control sobre los procesos administrativos sancionadores del ámbito pesquero por parte de las Unidades Orgánicas del Ministerio de la Producción, pudiendo registrar tanto los procesos actuales como aquellos procesos pendientes de trámite.

- Poder consultar el estado en que se encuentra cada uno de los procesos administrativos sancionadores, independientemente de la Unidad Orgánica que lo esté gestionando; haciendo que el proceso muestre la información en forma transparente tanto a las Unidades Orgánicas que lo requieran como a los propios administrados.

- Lograr una mayor interacción entre las Unidades Orgánicas que participan directa o indirectamente en este proceso, integrando la información de cada una de ellas, y así evitando islas de información. Además de compartir 
información con otros procesos que se realizan en el Ministerio de la Producción en general.

- Otorgar facilidades a las Unidades Orgánicas que participan en el proceso administrativo sancionador, haciendo que aquellas tareas similares y repetitivas sean estandarizados, ejecutándose en forma rápida y sencilla; agilizando de esta manera el proceso sancionador, y evitando la prescripción de procedimientos.

- Brindar seguridad a la información registrada, sabiendo que, quien y cuando se registró, modificó o eliminó la información, lo que permitiría hacer un análisis de trazabilidad de la información.

\subsection{Interesados}

\subsection{1. Áreas Impactadas y Principales Representantes}

Las Unidades Orgánicas del Ministerio de la Producción involucradas directamente con el proceso sancionador del ámbito pesquero son principalmente aquellas que pertenecen al Viceministerio de Pesca y Acuicultura, estas son:

- Dirección de Supervisión y Fiscalización; inicia el proceso sancionador realizando la función de supervisión o fiscalización de una actividad pesquera o acuícola.

- Dirección de Sanciones; determina la infracción cometida y establece la multa a imponer.

- Consejo de Apelación de Sanciones; analiza la solicitudes de apelación presentadas por los administrados ante una sanción impuesta.

- Oficina de Ejecución Coactiva; realiza el proceso de cobranza de la sanción impuesta.

Asimismo, se puede señalar que existen otras Unidades Orgánicas del Ministerio de la Producción involucradas indirectamente con el proceso sancionador, entre ellas se puede mencionar:

- Dirección General de Pesca para Consumo Humano Directo e Indirecto; que requiere conocer si una embarcación o una planta pesquera tiene pendiente 
por cancelar una multa impuesta, previamente a emitir un permiso de pesca o una autorización de procesamiento, respectivamente.

- Procuraduría Pública; recibida una demanda judicial de un administrado, debe conocer el detalle del proceso administrativo sancionador realizado por las Unidades Orgánicas a cargo para preparar la respuesta a la demanda presentada.

- Oficina de Contabilidad; debe conocer las sanciones impuestas en el proceso sancionador ya sea que éstas estén canceladas o no.

- Oficina de Gestión Documentaria y archivo; realiza la gestión de toda la documentación remitida a un administrado.

\subsubsection{Organigrama y Matriz RACI del Proyecto}

Figura 3.2

Organigrama del Ministerio de la Producción

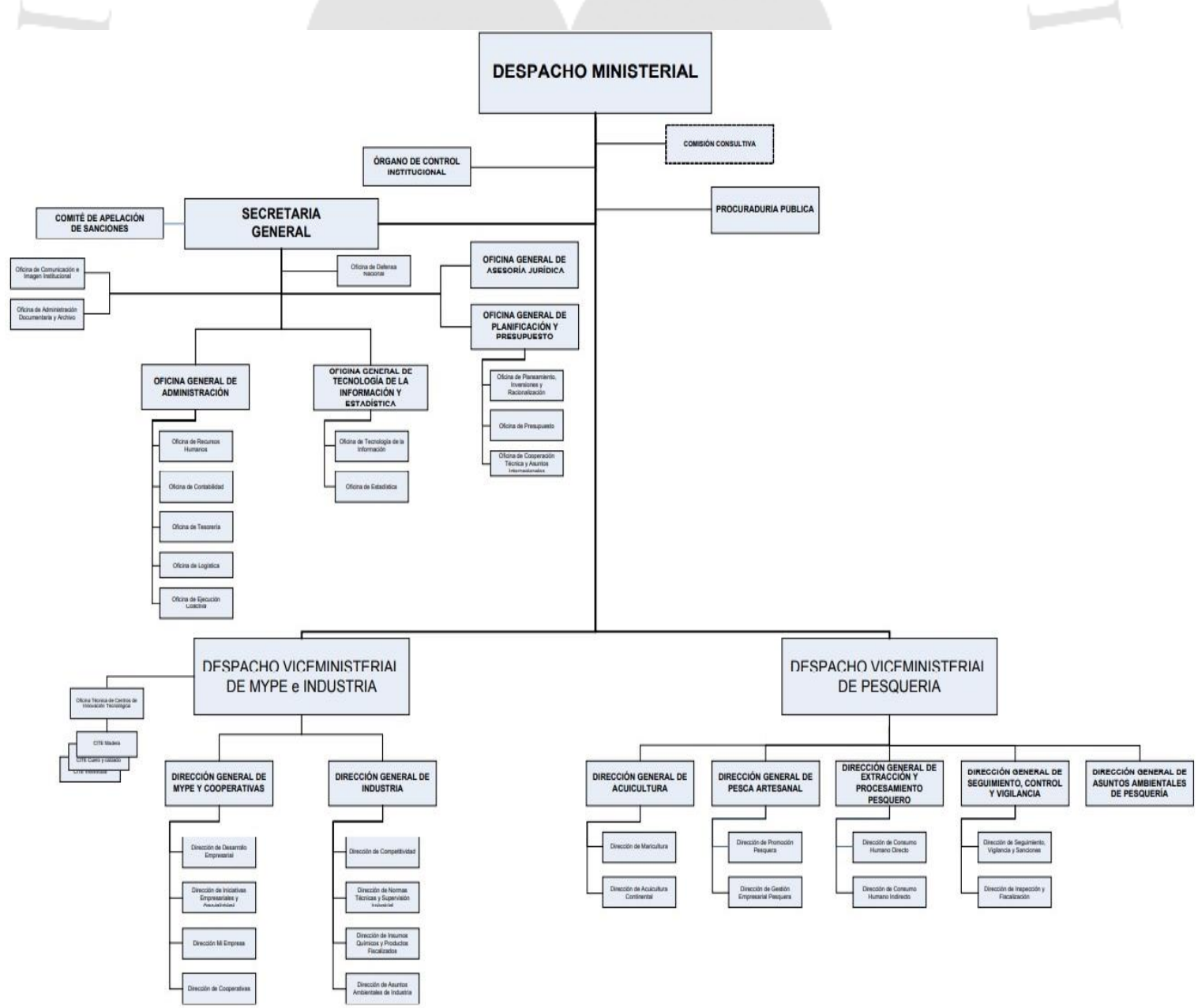

Fuente: Resolución Ministerial No 343-2012-PRODUCE 
Figura 3.3

Organigrama del Proyecto CONSAV

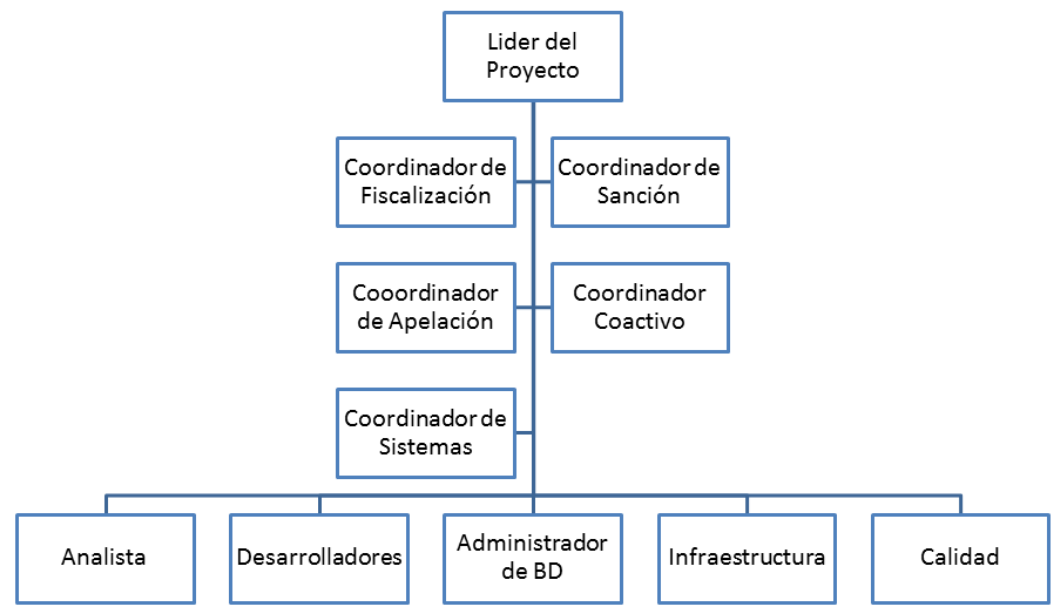

Fuente: Organigrama del proyecto CONSAV

Tabla 3.2

Matriz RACI del proyecto

\begin{tabular}{|c|c|c|c|c|c|c|c|c|}
\hline $\begin{array}{ll} & \text { Recurso } \\
\text { Actividad }\end{array}$ & $\begin{array}{l}\text { Lider } \\
\text { Proyecto }\end{array}$ & Coordinadores & $\begin{array}{l}\text { Coordinador } \\
\text { de Sistemas }\end{array}$ & Analista & $\begin{array}{l}\text { Adm. } \\
\text { BD }\end{array}$ & Desarrollador & Calidad & Infraestructura \\
\hline $\begin{array}{l}\text { Elaborar Acta de Inicio } \\
\text { del Proyecto }\end{array}$ & I & C & $\mathrm{R}$ & $A$ & 1 & I & 1 & I \\
\hline $\begin{array}{l}\text { Coordinar reuniones con } \\
\text { usuarios }\end{array}$ & I & A & $\mathrm{R}$ & C & I & I & 1 & 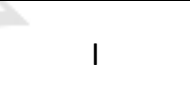 \\
\hline $\begin{array}{l}\text { Elaborar Actas de } \\
\text { reuniones }\end{array}$ & I & A & C & $\mathrm{R}$ & I & I & I & 1 \\
\hline $\begin{array}{l}\text { Implementar ambientes } \\
\text { (desarrollo, calidad, } \\
\text { producción) }\end{array}$ & & I & I & C & I & A & I & $\mathrm{R}$ \\
\hline Elaborar requerimientos & 1 & | & A & $\mathrm{R}$ & 1 & C & I & I \\
\hline $\begin{array}{l}\text { Elaborar y definir Casos } \\
\text { de Uso }\end{array}$ & I & I & $A$ & $\mathrm{R}$ & I & C & I & 1 \\
\hline Elaborar prototipos & I & I & $A$ & $\mathrm{R}$ & I & C & I & I \\
\hline Crear Base de Datos & I & I & C & A & $\mathrm{R}$ & I & I & I \\
\hline Desarrollar & I & I & C & A & I & $\mathrm{R}$ & I & I \\
\hline $\begin{array}{l}\text { Realizar pruebas } \\
\text { unitarias }\end{array}$ & I & I & C & A & I & $\mathrm{R}$ & C & I \\
\hline
\end{tabular}




\begin{tabular}{|l|c|c|c|c|c|c|c|c|}
\cline { 3 - 8 } $\begin{array}{l}\text { Elaborar Manual de } \\
\text { Usuario }\end{array}$ & $\mathrm{I}$ & $\mathrm{I}$ & $\mathrm{C}$ & $\mathrm{R}$ & $\mathrm{I}$ & $\mathrm{A}$ & $\mathrm{I}$ & $\mathrm{I}$ \\
\hline $\begin{array}{l}\text { Realizar pruebas de } \\
\text { calidad }\end{array}$ & $\mathrm{I}$ & $\mathrm{I}$ & $\mathrm{I}$ & $\mathrm{I}$ & $\mathrm{I}$ & $\mathrm{A}$ & $\mathrm{R}$ & $\mathrm{C}$ \\
\hline Capacitar a usuarios & $\mathrm{C}$ & $\mathrm{C}$ & $\mathrm{C}$ & $\mathrm{R}$ & $\mathrm{I}$ & $\mathrm{I}$ & $\mathrm{A}$ & $\mathrm{I}$ \\
\hline
\end{tabular}

Fuente: Organigrama del proyecto CONSAV

\subsubsection{Descripciones de las funciones del Bachiller en el Proyecto Profesional}

- La función principal que realizo en este proyecto es ser el analista de sistema, por lo cual elaboré la documentación requerida en esta etapa.

- Se participó en la elaboración del cronograma del proyecto, especificando las actividades a realizar, estimando el tiempo de su desarrollo y proponiendo la persona responsable de su ejecución.

- Participar en las entrevistas con los usuarios de las Unidades Orgánicas del Ministerio de la Producción que participan en el proyecto, obteniendo información para el diseño del flujo del proceso sancionador.

- Con la finalidad de cumplir los tiempos establecidos en el cronograma y las expectativas de los usuarios, se coordinó con los grupos de desarrolladores, de base de datos, de implementación y de calidad.

- Ayudar al administrador de base de datos en la elaboración del modelo de datos, definiendo los objetos (tablas, vistas y procedimientos) así como la forma en que se pueda registrar la información de trazabilidad requerida.

- Realizar pruebas del sistema previo a ser probados por el usuario final.

- Coordinar con el personal informático del proyecto para pasar del ambiente de desarrollo, al ambiente de calidad y finalmente al ambiente de producción.

- Participar en las capacitaciones a los usuarios, haciéndoles la inducción en el sistema desde que este se implementa en el ambiente de calidad hasta que sea desplegado en el ambiente de producción.

\subsubsection{Aporte del Bachiller en el Proyecto Profesional}

- Definir la estrategia de desarrollo estableciendo la prioridad de los módulos y de las interfaces a desarrollar. 
- Detallar los requerimientos de sistemas, coordinando los requerimientos de base de datos y la infraestructura necesaria para su implementación.

- Determinar las interfaces y dependencia que debería tener el sistema CONSAV con otros aplicativos o bases de datos.

- Hacer respetar las funcionalidades de las otras aplicaciones con las que se deben relacionar el sistema CONSAV, como por ejemplo el Sistema de Trámite Documentario - SITRADOC.

\subsubsection{Evaluación Económica}

Si bien el presente proyecto se desarrolla en una institución del Estado Peruano y se utiliza los recursos que esta proporciona, se brinda la siguiente información económica para demostrar que el proyecto es económicamente factible su desarrollo.

Los costos del desarrollo del sistema CONSAV están básicamente relacionados a los incurridos por los recursos humanos que requiere contratar la Oficina General de Tecnologías de la Información, estos corresponden a los programadores, personal de mesa de ayuda y testing, lo cual asciende a S/. 160,000.00. En el siguiente cuadro se detallan los costos incurridos por este concepto.

\section{Tabla 3.3}

Costos de recursos humanos del proyecto

\begin{tabular}{|c|c|c|c|c|}
\hline Descripción & $\begin{array}{c}\text { Remuneración } \\
\text { Mensual }\end{array}$ & Cantidad & $\begin{array}{c}\text { Total } \\
\text { Mensual }\end{array}$ & $\begin{array}{l}\text { Total Anual } \\
\text { (10 meses) }\end{array}$ \\
\hline $\begin{array}{l}\text { Programador } \\
\text { Senior }\end{array}$ & S/. 4,000.00 & 1 & S/. 4,000.00 & S/. 40,000.00 \\
\hline $\begin{array}{l}\text { Programador } \\
\text { Junior }\end{array}$ & S/. 3,000.00 & & S/. 6,000.00 & S/. 60,000.00 \\
\hline Testing & S/. 3,500.00 & 1 & S/. 3,500.00 & S/. 35,000.00 \\
\hline Mesa de Ayuda & S/. 2,500.00 & 1 & S/. 2,500.00 & S/. 25,000.00 \\
\hline & & & Total & S/. $160,000.00$ \\
\hline
\end{tabular}

Fuente: Recursos Humanos del Ministerio de la Producción 
Para iniciar del presente proyecto informático en el Ministerio de la Producción se contaba con la infraestructura requerida para su implementación, tanto el personal de las Unidades Orgánicas a cargo del procedimiento administrativo sancionador contaban con equipamiento de computadoras las cuales están conectadas a la red interna, y la Oficina de Tecnología de la Información tenia implementadas las bases de datos para su utilización, además de la capacidad para su almacenamiento.

Sin embargo existe un costo inicial del proyecto de S/. 25,000.00 que corresponde a la compra de 5 computadoras para el trabajo de los programadores senior, junior y del personal que realizará las pruebas (testing); cada computadora incluye el software licenciado (sistema operativo y herramienta de ofimática) y la garantía por 3 años. A continuación se detallan los costos de las computadoras compradas.

Tabla 3.4

Costos iniciales del proyecto

\begin{tabular}{|l|r|r|r|}
\hline \multicolumn{1}{|c|}{ Ítems } & Costo Unitario & Cantidad & Costo Total \\
\hline Computadora & S/. 3,500.00 & 5 & S/. 17,500.00 \\
\hline Garantía 3 años & S/. 1,000.00 & 5 & S/. 5,000.00 \\
\hline Sistema Operativo & S/. 250.00 & 5 & S/. 1,250.00 \\
\hline \begin{tabular}{l|r|r|r|} 
Herramienta \\
Ofimática
\end{tabular} & S/. 250.00 & 5 & S/. 1,250.00 \\
\hline
\end{tabular}

Fuente: Oficina de Logística del Ministerio de la Producción

Asimismo, de acuerdo a la información obtenida en el primer año del proyecto (año 2013), se registraron 18 resoluciones por prescripción, las cuales se asume como el beneficio que se tiene al implementar el presente de proyecto, ya que la intención es que éstas se puedan cobrar. En la Tabla No 3.5 se detalla el cálculo de S/. 166,500.00 que se tiene por este concepto. 
Tabla 3.5

Cálculo del monto de las resoluciones de prescripción

\begin{tabular}{|l|r|}
\hline \multicolumn{1}{|c|}{ Año 2013 } & \\
\hline Valor UIT & S/. 3,700.00 \\
\hline Cantidad de Resolución por Prescripción & 18 \\
\hline Sanción Promedio de UIT por Resolución & 2.5 \\
\hline Total & S/. 166,500.00 \\
\hline
\end{tabular}

Fuente: Dirección de Sanciones

Con la finalidad de evaluar la factibilidad del proyecto a través del cálculo del Valor Actual Neto (VAN) y de la Tasa Interna de Retorno (TIR), se utiliza la información obtenida en el periodo de su ejecución (10 meses) como información anual y así realizar una proyección a 10 años.

La información utilizada para este cálculo son los costos del personal y del inicio del proyecto, de las resoluciones prescritas que se deberían cobrarse, y se asume un costo de oportunidad del proyecto en un $15 \%$; se obtiene un VAN $=S / .7,622.00$ y un TIR = $23 \%$ por lo que al ser positivos se determina que es viable el presente proyecto.

Tabla 3.6

Cálculo del VAN y TIR

\begin{tabular}{lccccccccccc} 
Año & 0 & 1 & 2 & 3 & 4 & 5 & 6 & 7 & 8 & 9 & 10 \\
Resoluciones & & 166,500 & 166,500 & 166,500 & 166,500 & 166,500 & 166,500 & 166,500 & 166,500 & 166,500 & 166,500 \\
-Personal & & $-160,000$ & $-160,000$ & $-160,000$ & $-160,000$ & $-160,000$ & $-160,000$ & $-160,000$ & $-160,000$ & $-160,000$ & $-160,000$ \\
-Computadoras $/$ SW & $-25,000$ & & & & & & & & & & \\
\hline Flujo Economico & $-25,000$ & 6,500 & 6,500 & 6,500 & 6,500 & 6,500 & 6,500 & 6,500 & 6,500 & 6,500 & 6,500 \\
\hline \hline
\end{tabular}

Costo de oportunidad $15 \%$

VAN $\quad 7,622$

TIR $23 \%$

Fuente: Elaboración propia 


\subsubsection{Cronograma del Proyecto}

El proyecto se desarrolló en 10 meses, iniciándose en el agosto del año 2012, donde el módulo de fiscalización fue el primer que se desplegó en el ambiente de producción, lo cual ocurrió a los 3 meses de iniciado el proyecto; luego se desplegó el módulo de sanción a los 2 1 1/2 meses siguientes; para marzo del 2013 se había desplegado el módulo de apelación; y finalmente se desplegó el módulo coactivo en mayo del 2013. En el Anexo $\mathrm{N}^{\mathrm{o}} 4$ se muestra un cronograma detallado del proyecto.

Figura 3.4

Cronograma general del proyecto

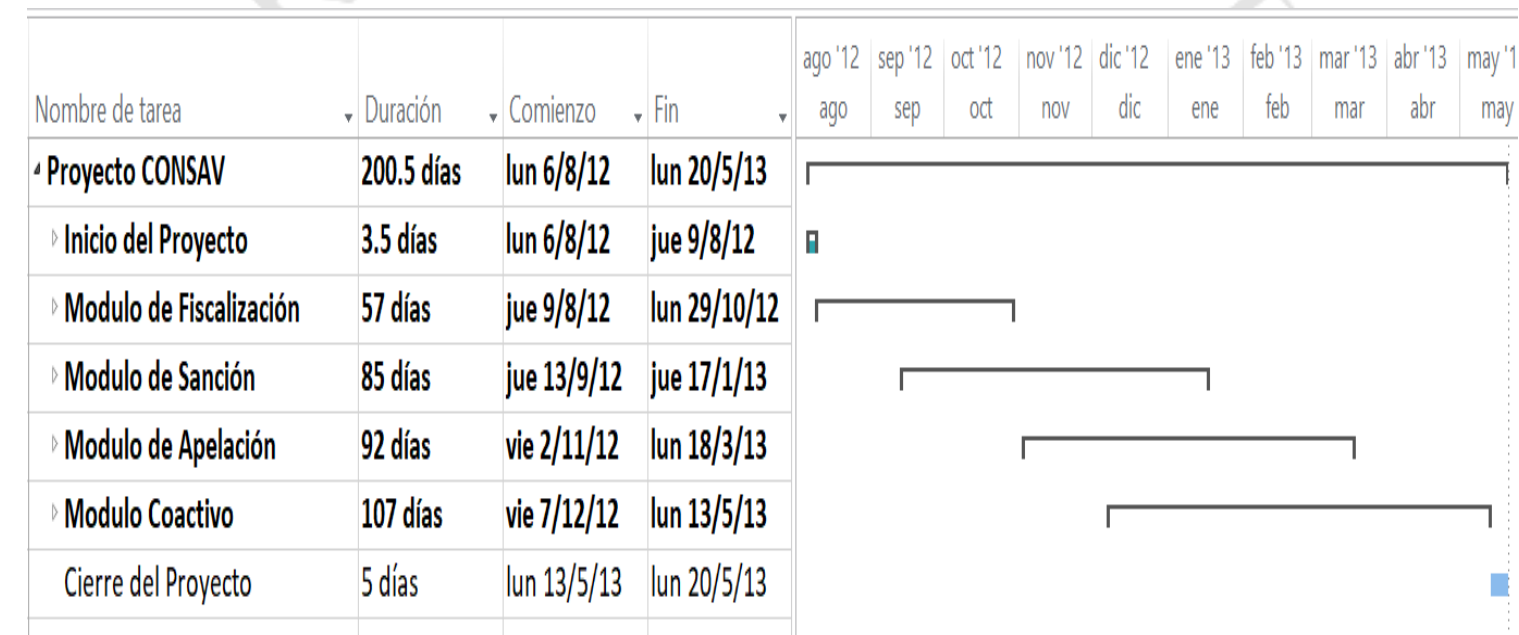

Fuente: Elaboración Propia 


\section{CAPÍTULO IV: DESARROLLO DEL PROYECTO}

\subsection{Análisis}

Uno de los principales retos en esta etapa fue entender en corto tiempo la lógica del proceso que se seguía en cada una de las Unidades Orgánicas que participan en el proceso; ya que entendiendo cada proceso se conseguiría un análisis del sistema en el que se refleje los requerimientos de los usuarios. Por ello se optó por analizar los diferentes módulos de manera progresiva y en el orden en el que se desarrollaba el proceso administrativo. Esto nos permitió entregar al equipo de desarrolladores, los módulos de las interfaces consensuados con los usuarios para iniciar su desarrollo, y asimismo nos permitió realizar el despliegue de los entregables en las fechas comprometidas con los usuarios de las Unidades Orgánicas.

Con la finalidad de entender más a detalle el procedimiento sancionador del ámbito pesquero, a continuación se detallan los grandes procesos que lo componen:

Figura 4.5

Flujo de proceso administrativo sancionador

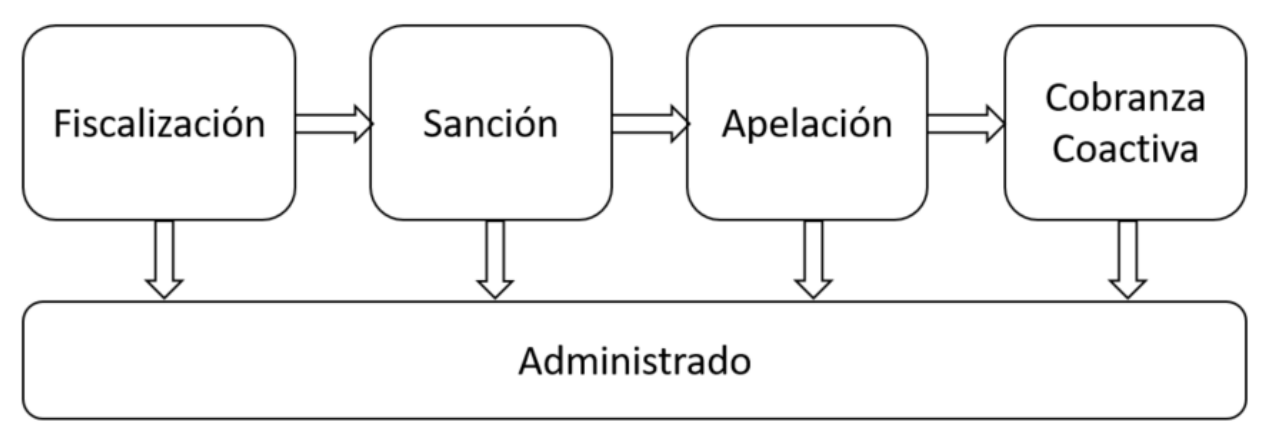

Fuente: Información del proyecto

- Fiscalización.- Ejecutado por la Dirección de Supervisión y Fiscalización encargada de evaluar las actividades que realizan las personas naturales y jurídicas con los productos hidrobiológicos del ámbito marítimo y continental. Evalúan las actividades realizadas para determinar si se requiere iniciar un proceso de sanción. En el caso que se amerite iniciar un proceso de sanción, se crea el expediente sancionador, especificando el motivo (porque), que persona, embarcación o planta cometió la infracción (quien), en qué lugar 
se cometió el hecho (donde y cuando). Finalmente el expediente sancionador creado es notificado al administrado para que tenga conocimiento del inicio del proceso.

- Sanción.- Se inicia cuando la notificación del expediente ha sido recibida por el administrado, iniciándose la elaboración de un Informe Legal, el cual determina el tipo de Resolución a emitir y donde se establece la infracción cometida y el monto a sancionar. Este proceso termina con la emisión de la Resolución Directoral notificada al administrado.

Figura 4.6

Principales procesos de la Dirección de Sanciones

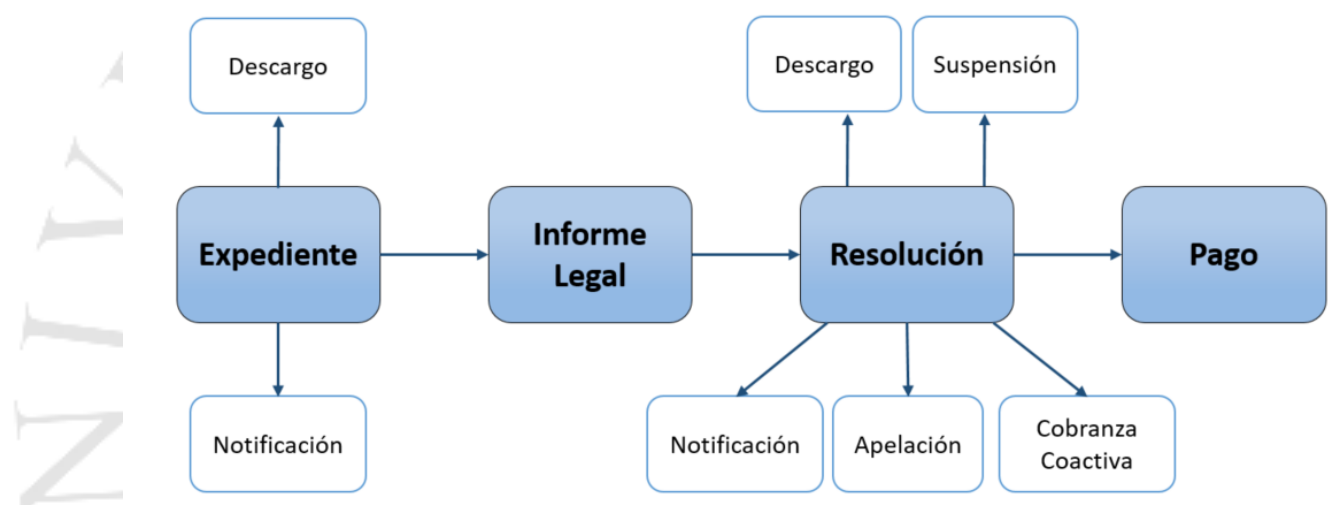

Fuente: Dirección de Sanciones

- Apelación.- Se inicia cuando un administrado apela o no está de acuerdo con la sanción impuesta en una Resolución Directoral. El Consejo de Apelación de Sanciones inicia el proceso creando el expediente de apelación el cual luego de evaluarse la documentación presentada por la Dirección de Sanciones y el escrito de apelación del administrado, emite una Resolución de Apelación en donde puede confirmar o modificar lo emitido en la Resolución Directoral.

- Coactivo.- Este proceso se encarga de cobrar la sanción impuesta, ya sea porque fue determinada por la Dirección de Sanciones o modificada por el Consejo de Apelación de Sanciones. Se inicia con la creación del expediente coactivo, luego se emiten Resoluciones de diferente índole tanto al administrado como a las entidades financieras. Finalizándose con el cobro total de la multa. 
Se identificó que las Unidades Orgánicas tenían registrado información del proceso sancionador en formatos propios (principalmente en formato Excel). Por ello se negoció con cada una de las Unidades Orgánicas para que agrupen, resuman y organicen la información que deseaban en una sola estructura, y que en esta misma el sistema CONSAV registre la información con el fin de mantenerla actualizada.

También se identificó que, como en todo procedimiento, se tenía una gran cantidad de información que se compartía con otros procedimientos, principalmente con los de trámite documentario, a través del cual se numeraba todos los documentos que generaba el procedimiento sancionador en sus diferentes etapas.

Durante la etapa de análisis se tuvo que aprender y utilizar los mismos términos utilizados por los usuarios (específicamente por los abogados) para hacerles entender el proceso que se estaba desarrollando. Por ejemplo, la fecha de recepción de un documento por parte de un administrado, es la fecha de notificación del documento.

Se tuvo que enseñar los objetos utilizados en el modelamiento de proceso a los usuarios de las Unidades Orgánicas que participaban en las definiciones del flujo de información para que entendiesen la lógica que se estaba desarrollando. A continuación se muestra el flujo general del proceso; y en el Anexo $\mathrm{N}^{\circ} 5$, se detalla el flujo del proceso administrativo sancionador desarrollado.

Riesgos presentados durante el análisis de la solución:

- No identificar de manera correcta el requerimiento del usuario, dado que un mismo usuario no tenía tiempo para absolver todas nuestras consultas; la información que nos proporcionaba un primer usuario era diferente a lo que expresaba otro usuario.

- No saber plasmar el requerimiento del usuario a través de una adecuada interface para que le facilite su trabajo.

- Vulnerar la información en otros aplicativos con lo que se debía interactuar el sistema CONSAV; dado que algunos usuarios solicitaban que el sistema realice ciertas funcionalidades que eran de otros aplicativos.

Problemas presentados durante el análisis de la solución:

- Cambios y rotación del personal que nos brindaba la información sobre los requerimientos que eran necesarios para construir la aplicación. 
- Utilizar los mismos términos de los usuarios, que en su mayoría son abogados, para hacerles entender el proceso que se estaba desarrollando.

- Hacer entender a los usuarios que ciertos requerimientos no se podían realizar ya que afectaba a otros aplicativos.

- Los diferentes usuarios de las Unidades Orgánicas tenían su propio formato de información (formatos en Word y Excel).

- Solicitar a los analistas y/o desarrolladores de otros sistemas el funcionamiento de los sistemas con los que debe interactuar el sistema CONSAV.

Productos entregados:

- Diagrama de flujo de datos del proceso administrativo sancionador pesquero, mostrándose el flujo entre las Unidades Orgánicas que participan. A continuación se detallan los principales procedimientos (fiscalización, sanción, apelación y coactivo). Ver Anexo $\mathrm{N}^{\circ} 5$ el flujo detallado de los procesos desarrollados.

Listado de requerimientos funcionales del Módulo de Fiscalización:

- Registrar la información de cualquier proceso de fiscalización que pudiese terminar como una posible sanción; como las ocurrencias registradas por los inspectores, o los informes de posicionamiento satelital de las actividades de embarcaciones, o los informes de límite máximo de captura de embarcación.

- Se utilizaría el Sistema de Trámite Documentario (SITRADOC) para la generación de los documentos tales como: numerar los Memorandos para comunicar a la Dirección de Sanciones el inicio del proceso sancionador; crear los Informes Técnicos sobre los procesos de fiscalización iniciados, numerar las Cédulas de Notificación así como también recibir información de los documentos de parte de los administrados.

- Crear el expediente de sanción, registrando el o los procesos de fiscalización relacionados al mismo.

- Crear la Cédula de Notificación del expediente de sanción, en la cual se comunica a la persona natural o jurídica que se ha iniciado un proceso de sanción. 
- Registrar la documentación presentada por los administrados luego de ser notificados.

Listado de requerimientos funcionales del Módulo de Sanción

- Crear el Informe Legal, registrando la infracción y la sanción correspondiente.

- Crear la Resolución Directoral de Sanción

- Crear hacia el o los administrados la Cédula de Notificación de la Resolución Directoral en base al SITRADOC.

- Recibir documentos (apelaciones) de parte de los administrados.

- Crear Memorando hacia la Oficina de Ejecución Coactiva o hacia el Consejo de Apelación de Sanción.

Listado de requerimientos funcionales del Módulo de Apelación

- Recibir el Memorando de Sanción y crear el Expediente de Apelación

- Crear el Informe de Apelación y la Resolución de Apelación, pudiendo corregir la infracción emitida en la Resolución Directoral de Sanción.

- Crear la Cédula de Notificación hacia los administrados, en base a la Resolución de Apelación.

- Recibir documentos de parte de los administrados.

- Crear el Memorando de devolución del expediente hacia la Dirección de Sanción.

Listado de requerimientos funcionales del Módulo Coactivo:

- Recibir el Memorando de Sanción y crear el Expediente Coactivo

- Permitir registrar las costas y los gastos al Expediente Coactivo

- Que el Módulo Coactivo calcule el interés de cada Expediente Coactivo en base a la información de la Resolución Directoral de Sanción o de la Resolución de Apelación emitida.

- Crear las Resoluciones Coactivas y sus correspondientes Cédulas de Notificación.

- Recibir documentos de parte de los administrados.

- Registrar los pagos realizados por los administrados.

Listado de requerimientos no funcionales de sistemas 
- Los usuarios debían acceder al sistema CONSAV a través de la intranet del Ministerio de la Producción, para lo cual debían estar inscritos previamente en ella e identificados a través de un usuario. Por ello la disponibilidad de la información debe estar accesible especialmente en el horario de las Unidades Orgánicas que utilizan dicha información.

- Los usuarios debían utilizar los recursos informáticos que les proporcionaba el Ministerio para acceder al sistema CONSAV, y poder registrar la información en el sistema.

- Se debía crear servicios para que el Sistema de Trámite Documentario (SITRADOC) pueda generar los números de los documentos que el sistema CONSAV requería, tales como: Memorando, Oficios, Informes, Cédulas de Notificación.

- Se debía interactuar con otros sistemas del ámbito pesquero tales como el Sistema de Pesquería, del cual se obtiene información de las embarcaciones y plantas pesquera e información de fiscalización.

- Además se debía utilizar información general que ya se tiene establecida y se utiliza en otros aplicativos informáticos, como por ejemplo la de personas naturales y jurídicas, así como la información de las ubicaciones geográficas del Perú.

- En cuanto a la seguridad de la información, se debía saber que, quién y cuándo se registró la información (trazabilidad de la información).

- Se debía mostrar información del proceso administrativo sancionador haciendo pública y transparente la información del mismo.

- En cuanto al desempeño del sistema, el tiempo de respuesta no debe exceder a los 10 segundos de realizada la transacción (registro, actualización, eliminación o consulta).

Listado de actores identificados para la Dirección de Supervisión y Fiscalización

- Analista.- Registra el proceso de fiscalización; proceso por el cual se determina el inicio de la sanción.

- Administrativo.- Registra los documentos presentados por los administrados adjuntándolos a un proceso administrativo.

- Abogado.- Elabora el Informe de Fiscalización y el memorando para remitir la documentación a la Dirección de Sanción. 
Listado de actores identificados para la Dirección de Sanciones

- Administrativo.- Recibe la documentación de la Dirección de Supervisión y Fiscalización, para crear el expediente de sanción, y que en coordinación con el Director asigna el expediente creado a un abogado de la Dirección de Sanción. Luego que el Director de Sanciones aprueba el proyecto de resolución de sanción, este numera la resolución y emite las cédulas de notificación haciendo de conocimiento a los administrados la sanción impuesta. Finalmente se encarga de crear los memorando hacia la Oficina de Ejecución Coactiva para que la sanción impuesta sea cobrada, o hacia el Consejo de Apelación de Sanción para que evalúen el recurso presentado.

- Abogado.- Elabora el Informe Legal y el borrador de la resolución de sanción para que sea evaluada por el Director.

Listado de actores identificados para el Consejo de Apelación de Sanciones

- Administrativo.- Recibe el memorando de la Dirección de Sanciones para crear el expediente de apelación; el cual en coordinación con el Director de Apelaciones asigna el expediente a un abogado.

- Abogado.- Crea el informe de apelación y elabora el proyecto de resolución de apelación, el cual numera cuando el Consejo lo aprueba. También crea las cédulas de notificación de la resolución de apelación y remite la documentación a la Dirección de Sanción para que continúe el proceso, creando el memorando de respuesta.

Listado de actores identificados para la Oficina de Ejecución Coactiva

- Administrativo.- Recibe el memorando de la Dirección de Sanciones y crea el expediente coactivo

- Abogado.- Recibe el expediente coactivo, elabora las resoluciones coactivas así como las cédulas de notificación que correspondan, y registra los pagos que los administrados realicen.

Se utilizó los diagramas de casos de uso para describir la interacción de los actores del sistema y sus funcionalidades. La noción de casos de uso y escenarios maneja el flujo del proceso desde la captura de requerimientos hasta las pruebas, y provee un canal 
coherente entre el sistema y el proceso de desarrollo. En el Anexo $\mathrm{N}^{\circ} 6$ se muestran los diagramas de casos de uso identificados en el proyecto.

Las herramientas utilizadas durante la etapa de análisis del sistema son:

- Herramientas de ofimática (Word, Excel) para elaborar la documentación requerida para el proyecto.

- Uso intensivo del correo electrónico institucional (Microsoft Outlook), que se utilizó para compartir y comunicar de los avances del mismo, además de solicitarles información del proceso sancionador; asimismo se utilizaba para citarlos a reuniones en las que requerían su presencia.

- Para diseñar el procedimiento sancionador, se utilizó la herramienta Bizagi Modeler versión 2.6, con la cual se tiene licenciada.

\subsection{Diseño}

El diseño del sistema debía permitir registrar los procesos sancionadores actuales e históricos (aquellos que estaban almacenados), pero manteniendo un orden y coherencia en el registro de la información, dado que al momento de implementar el sistema los expedientes obraban en manos de las Unidades Orgánicas, se debía diseñar que las interfaces brinden la posibilidad de registrar información de fases anteriores a la suya.

El sistema debe permitir consultar información general del proceso sancionador por lo cual se debe permitir consultar por diferentes atributos del proceso. Tal como se aprecia en el siguiente interfaz, en la cual se puede consultar información de un proceso por la numeración del expediente de sanción, o de la resolución de sanción, o del expediente de apelación o de la resolución de apelación. 
Figura 4.7

Interface de la consulta general de información

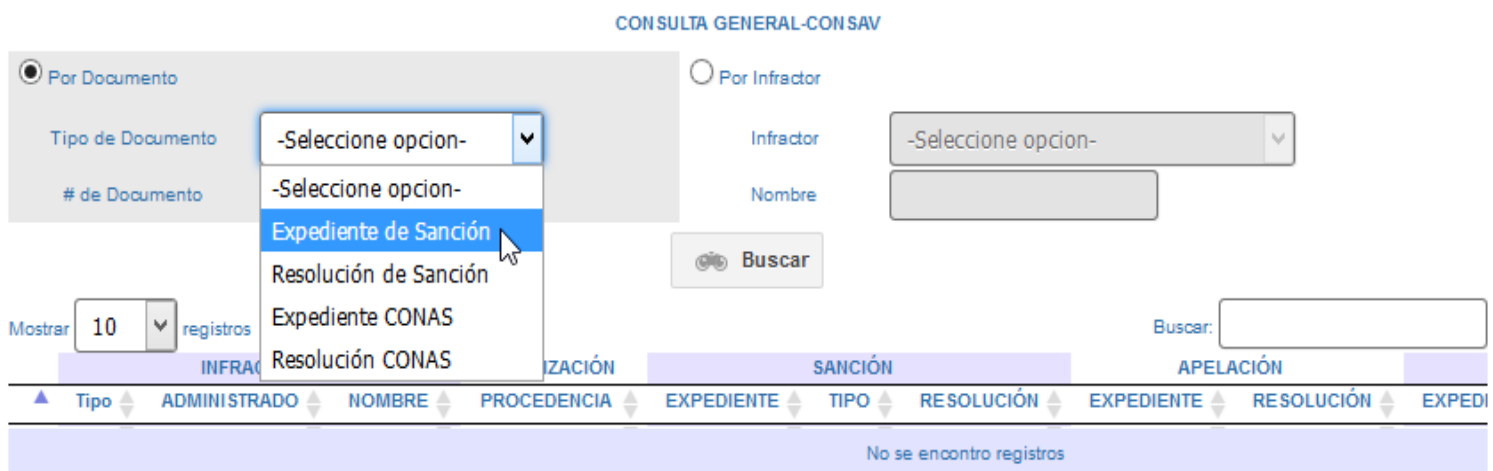

Fuente: Manual de usuario del sistema CONSAV

Se diseñaron los formatos de los memorando, cédulas de notificación y oficios; los cuales son constantemente utilizados por la Unidades Orgánicas, y donde su numeración se obtenía del Sistema de Trámite Documentario. Como ejemplo se muestra en el Anexo $\mathrm{N}^{\mathrm{o}} 7$ el caso de uso notificar un expediente sancionador.

Riesgos presentados durante la etapa de diseño de la solución:

- El acceso al sistema CONSAV se realiza a través de la intranet del Ministerio de la Producción, desarrollada en el año 2004, y teniendo como un resolución de pantalla de 800 x 600, para monitores CRT antiguos. Pero dada la adquisición de nuevas computadoras en los años 2010 y 2011, se tenía monitores con mayor resolución, por lo que el diseño de las interfaces en muchos casos no respetó la resolución de la intranet inicialmente diseñada, sino que además se diseñó el sistema para que sus interfaces sean adaptativas al dispositivo que se utilice para su visualización. Como ejemplo se muestra en el Anexo $\mathrm{N}^{\circ} 8$, la interfaz de creación de expedientes del módulo coactivo del caso de uso CU_21 - Crear Expediente Coactivo.

- Demora por parte de los usuarios en la aprobación de los prototipos presentados, consecuentemente demorándose la etapa de desarrollo.

- Registrar información incorrecta en otros aplicativos con los que se debía intercambiar información.

Problemas presentados durante la etapa de diseño de la solución: 
- Se demandó esfuerzo para diseñar la interfaces de intercambios de información con otros aplicativos ya implementados en el ambiente de producción, tal es el caso del Sistema de Trámite Documentario, con el cual se tuvo que coordinar con personal a cargo de este sistema, lo cual demandó un tiempo adicional, debiéndonos quedar en reuniones muchas veces fuera del horario de trabajo.

- En algunas oportunidades no se cumplió con presentar los prototipos con todas las funcionalidades solicitadas dentro del plazo establecido, haciendo demorar el inicio de la etapa de desarrollo del sistema.

- El diseño del sistema CONSAV debía permitir exportar la información hacia los formatos de los usuarios cuya estructura ya se había definido.

Los productos entregados durante la etapa de diseño de la solución son:

- Diagrama, diccionario y script de base de datos consensuado con los administradores de bases de datos de la Oficina de Informática. El diagrama de entidad relación de base de datos y descripción de las tablas del diccionario de datos se muestra a través de los Anexos $\mathrm{N}^{\circ} 9$ y 10 respectivamente.

- Prototipos de interfaces elaborados con Mokups, para mostrar a los usuarios las funcionalidades de las interfaces a desarrollar.

Las herramientas utilizadas en la etapa del diseño fueron:

- Herramientas de ofimática (Word, Excel) para elaborar la documentación.

- Uso del correo electrónico institucional para remitir los prototipos de las interfaces a los usuarios, con la finalidad que brinden sus observaciones o su conformidad.

- Se utilizó la versión 3.5 de la herramienta Erwin para el diseño de la base de datos.

- Se utilizó la versión gratuita del Mokups para diseñar los prototipos de las interfaces a ser mostradas a los usuarios finales. 


\subsection{Desarrollo}

El acceso del personal de las Unidades Orgánicas del Ministerio de la Producción al sistema CONSAV se realiza a través de la intranet de la institución, en el Anexo $\mathrm{N}^{\circ} 11$ se muestra la interface de la intranet del Ministerio de la Producción.

De acuerdo al análisis y diseño del sistema CONSAV, existe una integración de información con otros sistemas de información que se utiliza en el Ministerio de la Producción. Se puede mencionar el intercambio de información que existe con el sistema de Pesca, el cual brinda información de las embarcaciones pesqueras (nombre, número de matrícula, capacidad de bodega, y autorizaciones de pesca); o con el Sistema de Trámite Documentario (SITRADOC) que brinda la numeración y fecha de los documentos que se generan en el proceso sancionador, pudiendo visualizar el documento generado en el sistema CONSAV en el propio sistema SITRADOC y relacionado de manera adecuada.

Figura 4.8

Mapa de interacción con otros sistemas

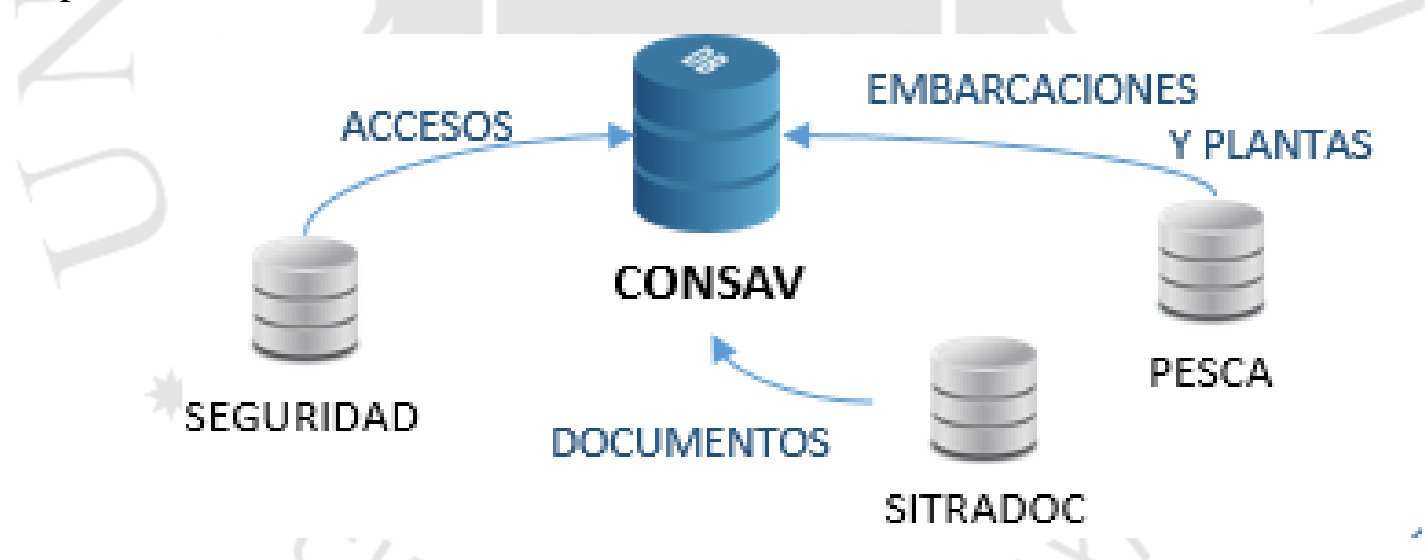

Fuente: Información del proyecto

Para el desarrollo del intercambio de información con el SITRADOC se coordina estrechamente con analistas y programadores de dicho sistema para reutilizar o desarrollar nuevos procedimientos que permitan obtener la numeración de los documentos que se requerían en el procedimiento sancionador, además de registrar en forma lógica la secuencia de documentos generados del proceso; con lo cual se lograba poder consultar la información de un proceso tanto a través del sistema CONSAV, como a través del SITRADOC. Los tipos de documentos utilizados en el proceso sancionador son: 
- Oficio, para comunicar la información de un proceso sancionador a entidades externas.

- Informes, documentos que emiten los evaluadores del proceso sancionador.

- Memorando, remisión de información de una Unidad Orgánica a otra.

- Resoluciones, documentos resolutivos de un proceso sancionador.

- Cédulas de Notificación, documentos a través de los cuales se comunica a los administrados de lo actuado

- Registros, documento presentado por un administrado, comunicando un hecho del proceso sancionador.

La contratación de nuevos programadores para el desarrollo del proceso sancionador implicó que los programadores que ya venían trabajado en la Oficina de Informática, tuviesen que revisar el código creado por los nuevos programadores sobre todo en aquellos procedimientos laboriosos, tales como:

- Remisión de memorando entre una Unidad Orgánica y otra, y la devolución del mismo.

- Cálculo del interés generado por falta de pago.

- Interfaces donde se debía interactuar con otros sistemas.

- El desarrollo de formatos establecidos, verificando que sea dinámica la información a mostrar.

Dada la alta rotación del personal en las Unidades Orgánicas que participaban en el proyecto, muchas veces se tuvo que rediseñar las interfaces, dado que al momento de presentar la interfaz desarrollada, la persona que brindó la información no era la misma que debía probar la funcionalidad desarrollada; con lo cual en algunos casos se retrasaba los tiempos de entrega de los módulos del sistema.

Se tuvo que modificar la forma de almacenar la información de trazabilidad, ya que inicialmente se diseñó el almacenamiento de toda la información en la misma tabla, pero al final se diseñó una tabla espejo donde se adicionó los campos para saber que, quién y cuándo se realizó la transacción. En el Anexo $\mathrm{N}^{\mathrm{o}} 10$ señala aquellas tablas transaccionales en las que se almacenó la información que nos permite hacer una auditoría o trazabilidad de la información. 
Figura 4.9

Servidores de base de datos

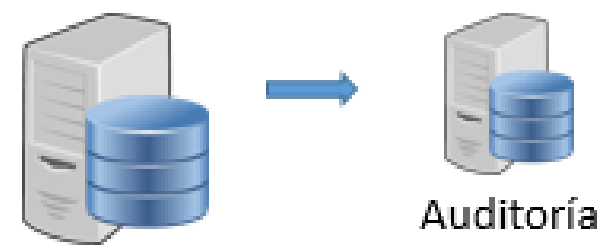

Transaccional

Fuente: Infraestructura de la Oficina General de Tecnologías

El uso de una herramienta Dreamweaver y el lenguaje de programación PHP versión 4.9 (2005) fue una limitante en la etapa de desarrollo, dado que los programadores constantemente tenían un malestar por utilizar dicha versión, dado que en el mercado para el año 2012/2013 ya estaba disponible la versión 5.4 del PHP; además tenía que cumplir con desarrollar usando un estándar que utilizan todas las aplicaciones desarrolladas, este estándar se detalla en el Anexo $\mathrm{N}^{\circ} 12$.

La etapa de calidad o pruebas del aplicativo se realizaba en el ambiente de desarrollo, debido a que la Oficina de Informática no tiene un ambiente específico para realizar las pruebas funcionales de las opciones desarrolladas, con lo cual esto acarreaba que en algunos casos los desarrolladores dejen de trabajar en un módulo u opción porque ésta debía ser utilizada por el área usuaria.

Riesgos presentados durante la etapa de desarrollo de la solución:

- Demora por parte de los desarrolladores para cumplir las fechas acordadas a ser presentadas las interfaces que componen el sistema.

- Que el personal de desarrollo haga uso de funcionalidades de otros sistemas para poder desarrollar los módulos del sistema CONSAV en forma más rápida.

Los entregables de esta etapa son:

- Código fuente de los archivos PHP versión 4.9.

- Archivos de base de datos (script) conteniendo los objetos desarrollados

- Comunicados de pruebas unitarias realizadas, éstos podían ser actas o correos electrónicos de las pruebas realizadas.

Las herramientas utilizadas en esta etapa son 
- Herramientas de ofimática (Microsoft Word y Excel).

- Correo electrónico institucional.

- $\quad$ Lenguaje de programación es PHP versión 4.9

- Herramienta de desarrollo Dreamweaver versión 7.0

- $\quad$ La base de datos utilizada es Microsoft SqlServer versión 2003

\subsection{Implementación}

El despliegue del sistema CONSAV en el ambiente de producción se realizó en forma ordenada, de acuerdo al flujo establecido en la etapa del análisis del sistema, ver el Anexo $\mathrm{N}^{\mathrm{o}} 1$ el flujo del procedimiento. Por ello se inició el despliegue con el módulo de fiscalización, para que las Unidades Orgánicas ingresen la información del proceso de fiscalización de sus expedientes que tenía en su custodia, luego se realizó el despliegue del módulo de sanciones, y en forma casi paralela se desplegó el módulo de apelación y coactivo.

El despliegue en el ambiente de producción del primer módulo ocasionó diferentes errores, especialmente al interactuar con los otros sistemas, por lo que se solicitó al administrador de base de datos, verificar que las estructuras de los ambientes de producción y desarrollo sean similares. Asimismo, se solicitó al encargado de infraestructura verificar las versiones de los componentes utilizados en ambos ambientes.

Existieron opciones que habiendo sido probadas por los desarrolladores y por el personal de las Unidades Orgánicas, estas daban error en el ambiente de producción, por lo que algunas veces el personal de desarrollo encargado de la opción desplegada debía corregir el error detectado en horas que no era utilizado dicha opción, porque una vez desplegado el módulo, este era utilizado inmediatamente. Se muestra en el siguiente diagrama el uso del primer módulo desplegado (fiscalización), en donde resalta la pendiente del año 2012 al 2013 cuando se inició el uso de dicho módulo. 
Figura 4.10

Cantidad de expedientes creados

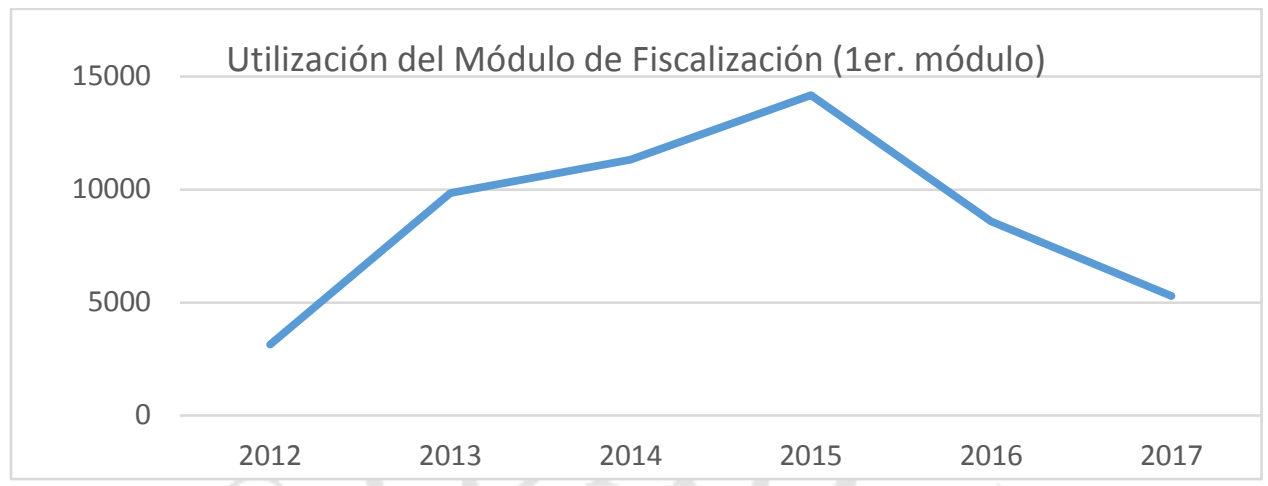

Fuente: Dirección de Supervisión y Fiscalización

Dado que el despliegue de los módulos se realiza en secuencia esto ocasionaba que en algunas oportunidades los usuarios de las Unidades Orgánicas se confundan en usar el ambiente de desarrollo con el de producción; por lo que constantemente se debía hacer hincapié en que la información que se mostraba era diferentes en los ambientes de desarrollo y producción.

Asimismo, como se estableció un orden para el desplieguen del sistema en el ambiente de producción, se recibía muchas preguntas por parte de los usuarios sobre cuando estaría el siguiente módulo ya que sabían que había información que se estaba registrando en un módulo previo al suyo, siendo de interés el cumplimiento de los plazos.

El despliegue en el ambiente de producción de cada opción desarrollada se realizaba luego que ésta había sido probada en el ambiente de desarrollo por la Unidad Orgánica correspondiente y previo a que el personal de la Oficina de Informática haya capacitado por lo menos una persona responsable de la funcionalidad desarrollada. El despliegue en el ambiente de producción se inicia cuando la Unidad Orgánica correspondiente remite el documento de "Solicitud de Pase a Producción" a la Oficina General de Tecnologías de la Información, la cual era firmada por el analista responsable del sistema, el coordinador informático, el encargado de la base de datos y el implementador (operador de red); en el Anexo $\mathrm{N}^{\circ} 13$ se muestra un ejemplo de este documento de uno de las opciones del módulo coactivo.

Con la finalidad de mostrar información del proceso sancionador, no sólo a las Unidades Orgánicas que directa o indirectamente participaban de este proceso, sino también para el administrado, se desplegó consultas en el portal del Ministerio de la 
Producción para mostrarles cierta información, tal como se muestra en la siguiente opción del portal a través del cual se publica información de la deudas de los administrado procesada por la Oficina de Ejecución Coactiva.

\section{Figura 4.11}

Consulta en el portal del Ministerio de la Producción

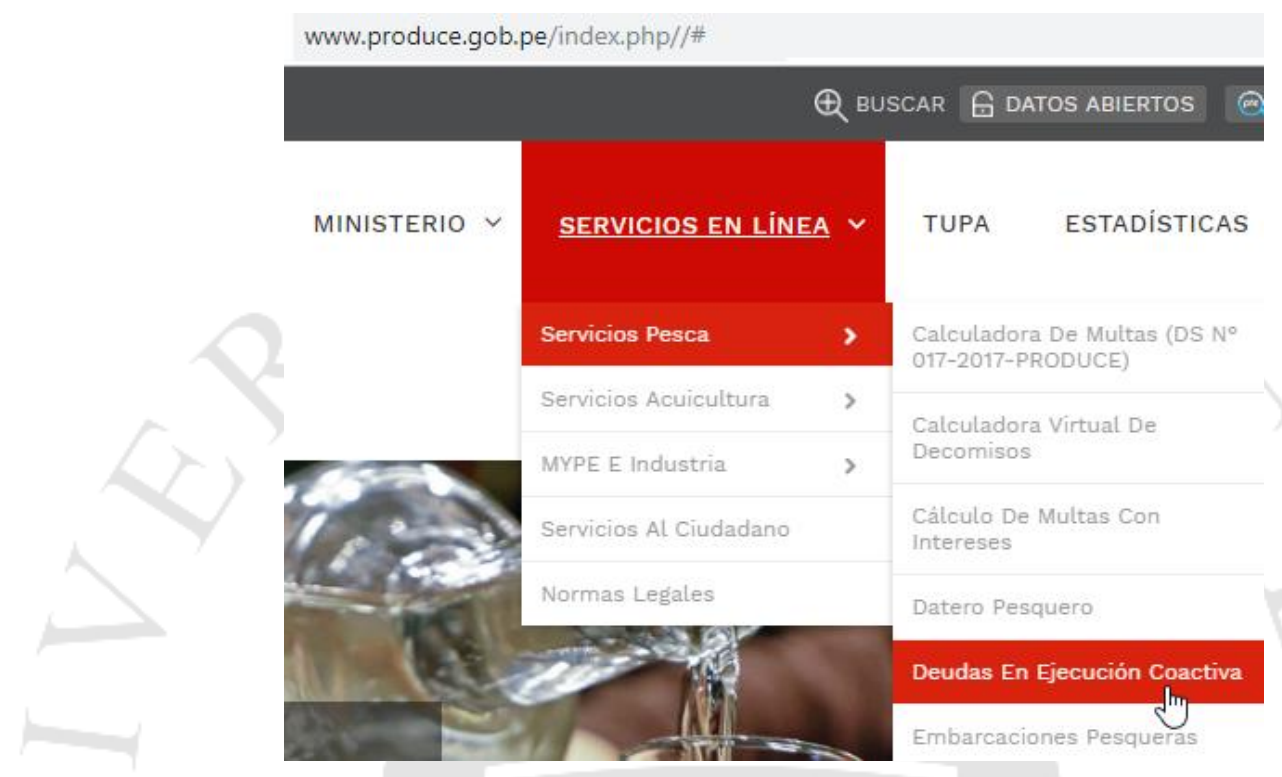

Fuente: Portal del Ministerio de la Producción

(http://www.produce.gob.pe/index.php/shortcode/servicios-pesca/deudas-en-ejecucion-coactiva)

Como parte de la documentación entregada al área de infraestructura para el despliegue de los módulos que componen el sistema CONSAV, se remitió los Informes de configuración y despliegue correspondientes, de cada uno de los módulos desarrollados. A continuación se muestra el diagrama de despliegue UML. 
Figura 4.12

Diagrama de despliegue

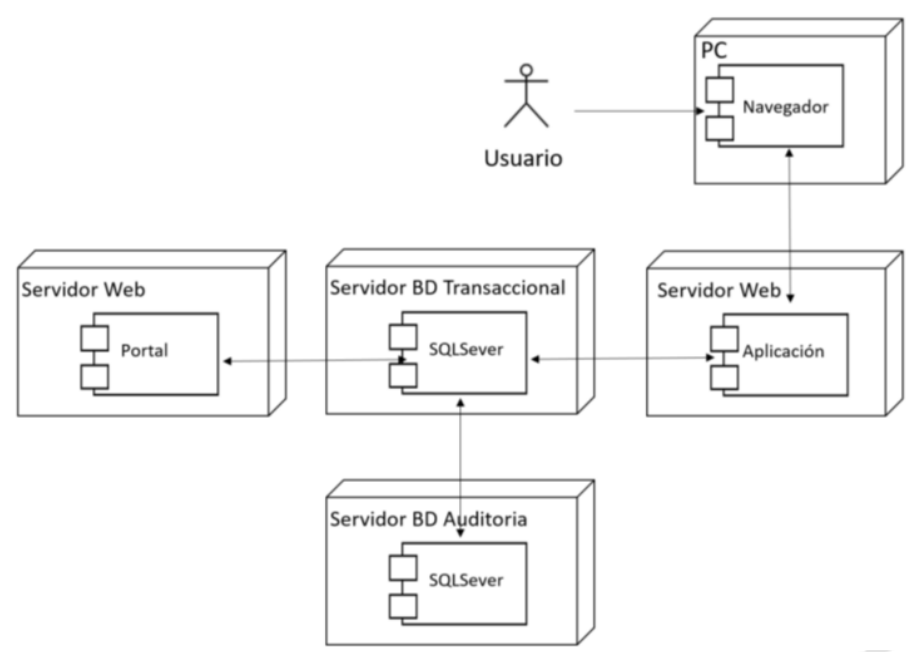

Fuente: Documentación de despliegue del sistema CONSAV

En el Anexo $\mathrm{N}^{\circ} 14$ se adjunta una descripción de los servidores utilizados, las características de la base de datos, los sistemas operativos utilizados; asimismo se muestra el Diagrama de Red del Ministerio de la Producción.

Cabe mencionar que en la Oficina de Tecnología de la Información del Ministerio de la Producción se tiene definidos determinados procesos para garantizar la seguridad de la información y el correcto funcionamiento del sistema. En dicho sentido se han definido procedimientos de backup incrementales a nivel de base de datos los cuales se ejecutan a las 12 y 18 horas, mientras que a las 23 horas se ejecuta un backup completo de la base de datos. Asimismo, para gestionar de manera adecuada las versiones de los aplicativos desplegados en el ambiente de producción, los encargados del área de infraestructura realizan un backup de la aplicación cada vez que se realiza un pase a producción con una nueva versión del sistema que se desea desplegar. 


\section{CONCLUSIONES}

Culminado el desarrollo y despliegue del proceso administrativo sancionador pesquero del Viceministerio de Pesca y Acuicultura en el Ministerio de la Producción a través del Sistema de Control Sancionador Virtual - CONSAV se puede concluir que:

- Se posibilitó a las Unidades Orgánicas registrar toda la información que realizan en materia sancionadora, pudiendo registrar tanto la información de los expedientes actuales como los históricos, además de mantener la integridad de la información con otros sistemas que requieren intercambiar información, tal como se muestra en el Anexo $\mathrm{N}^{\circ} 15$, donde se aprecia que tanto en el sistema CONSAV como en el sistema SITRADOC se ha generado un Memorando debidamente relacionado al recurso presentado.

- Se modificó la percepción de las Unidades Orgánicas respecto al proceso administrativo sancionador, otorgando una mayor claridad y transparencia de la información que cada una de ellas registra; como ejemplo se muestra en el Anexo $\mathrm{N}^{\mathbf{0}}$ 16 una consulta del portal del Ministerio de la Producción que muestra información de la Oficina de Ejecución Coactiva sobre los montos que debe pagar un administrado sobre una sanción impuesta.

- La sistematización del proceso administrativo sancionador permite identificar mejoras que se pueden realizar al proceso, además de normalizarlo y estandarizarlo; también lo hace más ágil sobre todo en la ejecución de aquellas tareas repetitivas que se realizan durante el proceso; como ejemplo se muestra en el Anexo $\mathrm{N}^{\circ} 17$ un formato de Memorando que se utiliza para remitir o solicitar información de una Unidad Orgánica a otra.

- Se logró bajar la cantidad de procesos de sanción prescritos, que por falta de iniciarlos en su momento estos prescribían imposibilitando emitir una Resolución de Sanción. Esto se logró gracias a una consulta que muestra el vencimiento de cada uno de los expedientes que tienen a su cargo los abogados, y que tiene acceso los Directores de la Unidades Orgánicas, vea el Anexo No 18. 


\section{RECOMENDACIONES}

El aporte del bachiller fue básicamente en las etapas de análisis y diseño del sistema, por lo cual se recomienda que:

- Con la finalidad de presentar un cronograma de un proyecto informático lo más cercano a la realidad, se debe tener presente si el usuario final tiene definido el flujo del procedimiento a implementar, si tiene toda la información necesaria para definir el proyecto, o por lo menos asegurarse que las personas que brindaran la información del proceso a sistematizar conozcan a cabalidad dicho proceso.

- Establecer un plan de comunicaciones para informar al sponsor y a los responsables del proyecto sobre los riesgos que existen para el cumplimiento del cronograma ofrecido, sobre todo cuando se cambia o rotan usuarios de las Unidades Orgánicas a cargo de brindar la información del proceso a sistematizar.

- Dado que el Ministerio de la Producción contempla dos Viceministerios, y en ambos se realizan las funciones de fiscalización y sanción, se recomienda ampliar el alcance del presente proyecto para sistematizar también el proceso administrativo sancionador del Viceministerio de MYPE e Industria.

- Mejorar el proceso administrativo sancionador agregándole otras funcionalidades como una pasarela de pagos, la cual facilitaría al administrado realizar el pago de la multa impuesta, haciéndose de conocimiento al Ministerio de la Producción del pago realizado en forma instantánea.

- Se recomienda hacer uso intensivo de la notificación electrónica, con la finalidad de agilizar el proceso de comunicación con el administrado, además de cuidar el medio ambiente utilizando menor cantidad de papeles y tintas de impresión.

- Finalmente se recomienda intercambiar la información del proceso administrativo sancionador con entidades externas como con la Dirección General de Capitanías, para que verifiquen la información de las embarcaciones pesqueras, previo a emitir un permiso. 


\section{REFERENCIAS}

Decreto Ley No 25977 (1992). Ley General de Pesca.

Ley No 27779 (2002). Ley de creación del Ministerio de la Producción.

Ministerio de la Producción (2013). Portal institucional http://www.produce.gob.pe

Ministerio de la Producción (2012). Resolución Ministerial N ${ }^{o}$ 343-2012-PRODUCE Reglamento de Organización y Funciones. 


\section{LOS ANEXOS NO ESTÁN DISPONIBLES POR CONTENER INFORMACIÓN CONFIDENCIAL}

